\title{
Nutrition in Pediatric Inflammatory Bowel Disease: A Position Paper on Behalf of the Porto Inflammatory Bowel Disease Group of the European Society of Pediatric Gastroenterology, Hepatology and Nutrition
}

\author{
${ }^{*}$ Erasmo Miele, ${ }^{\dagger}$ Raanan Shamir, ${ }^{\ddagger}$ Marina Aloi, ${ }^{\dagger}$ Amit Assa, ${ }^{\S}$ Christian Braegger, ${ }^{\prime}$ Jiri Bronsky, \\ ${ }^{\top}$ Lissy de Ridder, "Johanna C. Escher, ${ }^{\#}$ Iva Hojsak, ${ }^{\#}$ Sanja Kolacek, ${ }^{* *}$ Sibylle Koletzko, \\ ${ }^{\dagger \dagger}$ Arie Levine, ${ }^{\ddagger}$ Paolo Lionetti, ${ }^{*}$ Massimo Martinelli, ${ }^{\S \S}$ Frank Ruemmele, ${ }^{\prime \prime I I}$ Richard K. Russell, \\ ${ }^{\dagger \dagger}$ Rotem Sigall Boneh, "Iohan van Limbergen, ${ }^{\# \#}$ Gigi Veereman, and ${ }^{*}$ Annamaria Staiano
}

\begin{abstract}
Background and Aims: A growing body of evidence supports the need for detailed attention to nutrition and diet in children with inflammatory bowel disease (IBD). We aimed to define the steps in instituting dietary or nutritional management in light of the current evidence and to offer a useful and practical guide to physicians and dieticians involved in the care of pediatric IBD patients.

Methods: A group of 20 experts in pediatric IBD participated in an iterative consensus process including 2 face-to-face meetings, following an open call to Nutrition Committee of the European Society of Pediatric Gastroenterology, Hepatology and Nutrition Porto, IBD Interest, and Nutrition Committee. A list of 41 predefined questions was addressed by working subgroups based on a systematic review of the literature.

Results: A total of 53 formal recommendations and 47 practice points were endorsed with a consensus rate of at least $80 \%$ on the following topics: nutritional assessment; macronutrients needs; trace elements, minerals, and vitamins; nutrition as a primary therapy of pediatric IBD; probiotics and prebiotics; specific dietary restrictions; and dietary compounds and the risk of IBD.

Conclusions: This position paper represents a useful guide to help the clinicians in the management of nutrition issues in children with IBD
\end{abstract}

Key Words: Crohn disease, enteral nutrition, inflammatory bowel disease, nutrition, nutritional therapy, pediatrics, ulcerative colitis

(JPGN 2018;66: 687-708)

\section{What Is Known}

- A growing body of evidence supports the need for detailed attention to nutrition and diet in children with inflammatory bowel disease.

- Despite the increasingly recognized importance of the issue, no specific pediatric dietary guidelines have been published to date.

\section{What Is New}

- We provide clear recommendations to better define the steps in instituting nutritional management in light of the current evidence.

- This position paper represents a useful practical guide to help physicians and dieticians involved in the care of pediatric inflammatory bowel disease patients.

nflammatory bowel diseases (IBD), including Crohn disease (CD), ulcerative colitis (UC), and IBD-unclassified (IBD-U), are chronic and relapsing intestinal disorders, causing abdominal pain, diarrhea, rectal bleeding, and weight loss. Therefore, it is not surprising that parents and children with IBD believe that diet is relevant to their child's condition and that they try to modify their

Center, Sackler School of Medicine, Tel-Aviv, Israel, the $\ddagger \ddagger$ Meyer Children Hospital, University of Florence, Florence, Italy, the $\S \S$ Université Sorbonne Paris Cité, Université Paris Descartes, and Assistance publique-hôpitaux de Paris, Hôpital Necker-Enfants malades, Service de gastroentérologie pédiatrique, Paris, France, the ||||Department of Paediatric Gastroenterology, The Royal Hospital for Children, Glasgow, Scotland, the $\boldsymbol{\top}_{\text {Department of Pediatrics, Division }}$ of Pediatric Gastroenterology \& Nutrition, IWK Health Centre, Dalhousie University, Halifax, Nova Scotia, Canada, and the \#\#Department of Paediatric Gastroenterology and Nutrition, University Hospital Brussels, Free University Brussels, Brussels, Belgium.

Address correspondence and reprint requests to Annamaria Staiano, MD, Department of Translational Medical Science, Section of Pediatrics, Via S. Pansini, 5, 80131 Naples, Italy (e-mail: staiano@unina.it). 
diet accordingly. In particular, children with IBD often tend to avoid foods more than they would specifically need to. Thus, a growing body of evidence supports the need for detailed attention to nutrition and diet in children with IBD. Indeed, the relationship between nutrition and IBD encompasses several areas including nutritional support for malnourished patients, the use of exclusive enteral nutrition (EEN) as primary therapy for treatment of $\mathrm{CD}$, and the role of specific nutrients as a risk factor for disease development (1). There is wide variation in the dietary behaviors of children and the strength of recommendations for them, although most physicians do not routinely endorse specific diets for patients with IBD (2). Dietary factors may have beneficial or deleterious effects. Simple advice regarding avoidance of some foods without balancing the diet with recommended alternatives may inadvertently reduce the overall amount of calories, macronutrients, and micronutrients provided, contributing to the malnutrition and specific nutritional deficiencies in pediatric IBD patients $(3,4)$.

Recently, on the basis of the increasing knowledge regarding the efficacy of EEN for the induction of remission of pediatric $C D$, several attempts have been made to define new therapeutic avenues for the dietary treatment of pediatric IBD. Nevertheless, to date, in addition to the use of EEN, most "best-evidence" guidelines offer no recommendations for the use of specific diet in the therapy of IBD (5).

Thus, the purposes of this position paper are to define the steps in instituting dietary or nutritional management in light of the current evidence and to offer a useful and practical guide to physicians and dieticians involved in the care of pediatric IBD patients.

\section{METHODS}

A panel of experts was selected in April 2016 after an open call among the Pediatric IBD Porto Group, the IBD Interest Group, and the Nutrition Committee of the European Society of Pediatric Gastroenterology, Hepatology and Nutrition (ESPGHAN). The first face-to-face meeting resulted in organizing the position paper into 7 different sections, namely, nutritional assessment; macronutrients needs; trace elements, minerals and vitamins; nutrition as a primary therapy of pediatric IBD; probiotics and prebiotics; specific dietary restrictions; and, dietary compounds and the risk of IBD. Within these 7 sections a total of 10 topics were then assigned to 10 different working subgroups. Each working subgroup was asked to define the most relevant questions within their specific topic and to perform a literature search using Medline-PubMed and the Cochrane Library databases with appropriate search strategies (available upon request) using a last search date of May 1, 2016. Subgroups were also asked to grade the levels and the quality of evidence using the classification system of the Oxford Centre for Evidence-Based Medicine (http:// www.cebm.net/mod_product/design/files/CEBM-Levels-ofEvidence2.1.pdf). Questions were answered using the results of systematic literature searches and the resultant expert opinions. A total of 2 faceto-face meetings were held in Athens and Vienna to achieve consensus on formulate and agree on all of the recommendations. All group members interacted during these 2 face-to-face meetings, by iterative e-mails in the form of a modified Delphi process and by an e-platform. All recommendations were voted on and accepted when at least $80 \%$ agreement was achieved.

\section{NUTRITIONAL ASSESSMENT}

\section{Dietary History}

\section{Is there a need for regular dietary assessment in children with} IBD?

\section{Statement:}

- The assessment of dietary intake should be an integral part of the follow-up of pediatric IBD patients (Evidence Level [EL] 3).

Patients with IBD can tend to self-impose elimination diets to control the symptoms such as diarrhea and abdominal pain (6). The most commonly excluded foods are grains $(29 \%)$, milk $(28 \%)$, vegetables $(18 \%)$, and fruits (11\%) (6). Studies on dietary quality and nutritional intake of IBD patients have used different assessment tools and only 2 studies specifically address issues in children
Competing interests statement: E.M. received grant/research support from Valeas, served member of advisory board for Abbvie and as a speaker for the following companies: Angelini, Bioprojet, Ferring, Humana, Milte, Takeda; R.S. received grant/research support from Abbott and Enzymotec, served as member of advisory board for Danone Nutrition Institute, served as a speaker for Abbott, Enzymotec, Nestle Nutrition Institute, Nutricia and served as a consultant for Enzymotec, NGS, and Nutrinia; M.A. served as a member of advisory board and as a speaker for Abbvie; A.A. received grant/research support from Abbvie, Jannsen, and Rafa and served as a speaker for Abbvie; J.B. served as member of advisory board for MSD and Nutricia, served as a speaker for Nutricia, Nestle, Abbvie, MSD, and Biocodex; L.d.R. received grant/research support from Pfizer, served as a member of advisory board for Shire and Abbvie, and served as a speaker for Mundipharma and Pfizer; J.C.E. received grant/research supports from MSD and served as member of advisory board for Janssen and Abbvie; I.H. served as a speaker for BioGaia and Nutricia, and as consultant for Farmas and GM Pharma; S.K. received grant/research supports from Abbvie, BioGaia, Hospira, Falk, MSD Pharmas, and Wurth, and served as speaker for Abbott, Abbvie, BioGaia, Danone, Fresenius, MSD, Medis, Nestle, Nutricia, and Oktal Pharma; S.K. received grant supports from Mead Johnson, served as member of advisory board for Boehringer Ingelheim, Nestle, Danone, Nutricia, Biocodex, Shire, and served as a speaker for Centocor, Danone, Nestle Nutrition Institute, and Hipp; A.L. received grant/ research supports from Nestle, served as a member of advisory board for Jannsen and as a speaker for Nestle, Jannsen, and Abbvie; P.L. served as member of advisory board for Abbvie and Hospira and served as a speaker for Abbvie, Hospira, Danone, and Nestle; F.R. received grant/ research supports from Nestle Nutrition Institute, Abbvie, MSD, Janssen, and Centocor, served as a member of advisory board for Nestle Nutrition Institute, Nestle Health Science, Danone, Mead Johnson, Nutricia, Takeda, Celgene, Biogen, Shire, Pfizer, Therakos, and served as a speaker for Abbvie, Danone, Nutricia, and Nestle; R.K.R. received grant/research supports from Nestle Health Sciences, served as member of advisory board for Therakos, Abbvie, Vifor, Janssen, Shire, Cow \& Gate, Mead Johnson and served as a speaker for Nestle Health Science, Abbvie and Celltrion; R.S.B. served as a speaker for Nestle; J.v.L. received grant/research supports from Nestle Health Science, Abbvie, Janssen, and GSK, served as member of advisory board for Nestle Health Science, Abbvie and Janssen, and served as a speaker for Nestle Health Science, Abbvie and Janssen; G.V. served as member of advisory board for Boehringer, Ingelheim and as a speaker for Mead Johnson; A.S. received grant/research supports from Aboca, D.M.G. Italy, Milte, Nestle, served as member of advisory board for Sucampo and as a speaker for Aboca, Angelini, Danone, D.M.G. Italy, Menarini, Milte and Valeas.

Disclaimer: ESPGHAN is not responsible for the practices of physicians and provides guidelines and position papers as indicators of best practice only. Diagnosis and treatment is at the discretion of physicians.

Copyright (1) 2018 by European Society for Pediatric Gastroenterology, Hepatology, and Nutrition and North American Society for Pediatric Gastroenterology, Hepatology, and Nutrition

DOI: $10.1097 / M P G .0000000000001896$ 
$(7,8)$. The diet of IBD patients differed significantly from that of healthy controls and/or recommended daily allowance (RDA). Most commonly, intake was significantly lower for energy, fibers, and carbohydrates and for several vitamins (mostly fat soluble and vitamin $\mathrm{C}$ ) and minerals ( $\mathrm{Ca}, \mathrm{P}, \mathrm{Mg}$, $\mathrm{Fe})$. In children, both studies showed significantly decreased intake of energy, $\mathrm{Ca}$, and $\mathrm{Fe}(7,8)$. Poor dietary intake is consistent in both active disease and in remission additionally in both UC and CD (7).

Which method of dietary assessment is preferable and how often should it be performed?

\section{Statement:}

- A 3- to 5-day dietary record (DR) is recommended for the assessment of dietary intake (EL 4).

\section{Practice points:}

- No current method can give a complete snapshot of dietary intake over time.

- In the follow-up of patients with IBD, the ideal is to repeat the 3- to 5-day DR (in quality and quantity) twice a year in younger children, and once a year in adolescents, when found appropriate by the treating physician and/or dietician.

Methods used to assess dietary intake of IBD patients differ, and none suit all purposes (9). The food frequency questionnaire was standardized and validated, and performs well to investigate the relationship between a certain type of diet or dietary component and the risk for disease (10). The 3-to 5-day $\mathrm{DR}$ is better equipped for quantitative evaluation of energy and nutrient intake. Several studies have compared the performance of food frequency questionnaire and DR with differing results $(11,12)$. Recently published guidelines on nutritional care for children with cystic fibrosis recommend to use the 3- to 5-day DR every 3 months in children and every 6 months in adult patients (13). Because nutritional risks are less severe in children with IBD, it seems reasonable to assess dietary intake at least twice per year in small children $(\leq 5$ years) and once per year (every 12 months) in older children and adolescents or additionally whenever deemed necessary by the physician and/ or dietician.

\section{Anthropometry, Body Composition, Puberty}

What is the importance and etiology of undernutrition?

\section{Statement:}

- Malnutrition and impaired linear growth can be markers of disease activity; their restoration should be considered as a treatment goal (EL 2).

Linear growth impairment can precede any other symptom by many years in up to $46 \%$ of pediatric patients with CD (14-16). In the $80 \mathrm{~s}$ and the $90 \mathrm{~s}$ the prevalence of growth retardation and malnutrition were around $24 \%$ to $46 \%$
(15,17-19), More recent studies such as population cohorts (20), and multicenter registries $(21,22)$ report significantly decreased body mass index (BMI) at diagnosis in $17 \%$ to $32 \%$, and poor growth in $8 \%$ to $10 \%$. Furthermore, impaired linear growth persists in a significant proportion of patients with CD irrespective of the treatment modality, and results in decreased final adult height in $11 \%$ to $35 \%$ of patients with the mean difference reaching $7 \mathrm{~cm}$ less than genetic height potential (22-25). In UC patients, malnutrition and stunted growth affect a lower proportion of patients $(5 \%-12 \%)$ at diagnosis and do not usually persist at follow-up (24).

In the pathogenesis of growth retardation, chronic undernutrition, inflammation $(3,26-28)$, genetic background reflected in parents' heights (24), and recently discovered gene polymorphisms $(24,29-31)$ are all important contributors. Steroids may impair growth by a direct effect on the growth plate contrasted with the beneficial effect of resolving inflammation with short-term treatment or low doses. Of note, not all studies found a significant difference in growth and bone mineralization with respect to treatment with steroids $(19,21,26,32-35)$. For children with UC, diarrhea with blood loss, abdominal pain, anorexia, and the effects of drug therapy are the main contributors to the pathogenesis of undernutrition.

Although it will be not thoroughly analyzed within this paper, it has to be underlined that a variable percentage of children with IBD ranging from $10 \%$ to $30 \%$ may present with obesity at diagnosis $(36,37)$. This percentage seems not to differ from the general population and it is in line with the parallel obesity epidemic (36). It is still unclear whether these patients may have poorer disease outcomes, but it has been suggested that obese patients with IBD may have suboptimal response to therapies (38). Therefore, a weight loss should be envisaged as a possible adjunctive therapeutic intervention.

\section{Is body composition impaired in children with IBD?}

\section{Statement:}

- Lean body mass is decreased in children with IBD, particularly in CD. This deficit may persist after clinical remission (EL 2).

\section{Practice point:}

- The impact of an intervention on body composition should be included as a treatment outcome in clinical trials.

A recent systematic review examining body composition in IBD included 22 studies of which 6 were prospective, 11 cross-sectional and others examined specific interventions (eg, treatment, resection) (39). The general conclusions of the systematic review are that children with IBD have reduced lean body mass compared to control subjects. Most data originate from children with $\mathrm{CD}$. After remission this deficit persisted. Studies comparing children with CD to children with UC found greater lean body mass deficits are present in children with $\mathrm{CD}$. The findings on body fat were inconsistent, varying from decrease to augmentation and no change. There was no evidence found that alterations in body composition were related to gender or disease activity. One study, however, reported persistent deficit in lean body mass in girls, even in remission (40). 


\section{Puberty}

Is IBD-associated with delayed pubertal development?

\section{Statement:}

- IBD can be associated with delayed pubertal development (EL 2).

\section{Practice point:}

- Pubertal stage should be assessed regularly from diagnosis in children age 10 years and older, and at least annually during follow-up visits until puberty is completed.

It has long been known that IBD in children is associated with pubertal delay (41). Despite improved treatment strategies, pubertal development must be monitored closely because it still leads to severe complications such as decreased mineral bone density, short stature, and lack of self-esteem $(42,43)$. Catch up growth with treatment is better in early puberty (44). When assessing body composition, the pubertal stage needs to be taken into account. Genders differ in lean body mass accrual: girls before and boys during puberty (39).

How and when to determine nutritional status and to measure linear growth?

\section{Statements:}

- Weight, height, and BMI $z$ scores should be used for assessment of the nutritional status at each clinic visit (EL 2).

- Longitudinal linear growth reflects disease course; it should be assessed every 6 months by measuring height velocity $z$ scores or variations in height-forage standard deviation score (SDS) (EL 2).

\section{Practice points:}

- Anthropometric measures should be plotted into the appropriate growth charts

- Height velocity depends on the pubertal status. Therefore, both have to be determined concurrently.

Nutritional status is currently being expressed mainly as the BMI SDS ( $z$ score) (20), but because BMI can be normal in stunted children, the height and parental height should always be considered too $(13,24)$. To assess growth, a height percentile or height-for-age $\operatorname{SDS}(z$ score $)$ is appropriate for a single measurement. In children with IBD longitudinal linear growth is, however, more important as it reflects disease course and treatment success. In that respect, a change in the height SDS and a height velocity SDS for a period of 6 to 12 months are the methods of choice. The height velocity SDS reflects growth over a defined period (27), but it also depends on the patient's pubertal status. Therefore, in children with pubertal delay the change in height SDS could be used as a reliable marker of the longitudinal growth (26). In the recent European Crohn's and Colitis Organization (ECCO)/ESPGHAN consensus guidelines, the height velocity over a period of 6 to 12 months expressed in SDS has been recommended as the best measure to monitor growth in patients with $\mathrm{CD}$, and if unavailable, change of the height-for-age $z$ score is appropriate (45).

\section{MACRONUTRIENTS AND ENERGY NEEDS IN INFLAMMATORY BOWEL DISEASE}

\section{Definition}

Macronutrients are proteins, carbohydrates, and fat.

Are there increased energy and macronutrient requirements in pediatric IBD?

\section{Statement:}

- There is insufficient evidence that pediatric IBD patients have increased energy and macronutrient requirements compared to healthy children (EL 4).

\section{Practice point:}

- In the case of insufficient intake dietary consulting is recommended. The general intake may be increased on an individual basis, by increasing food intake and food fortification. If those are not enough supplemental formula may be recommended or increasing caloric density of supplements. When needs cannot be met by oral feeds, adequate nutrition can be provided by nasogastric feeds.

Several studies have investigated energy requirements in children with inconsistent results. Evidence regarding Resting Energy Expenditure (REE), which is the energy requirement for an individual in resting condition that approximates basal metabolic requirements, is conflicting. An increase in REE in patients with active $C D$ was demonstrated in several studies in adults (46-48) and in children $(49,50)$. Other studies, however, suggested that this is due to changes in body composition rather than the hypermetabolism found in adults $(51,52)$ and in children $(53)$. Data from adult studies cannot be extrapolated to pediatrics because children have higher energy requirements relative to their body size during growth.

Several studies compared predicted REE to measured REE; 6 studies found no significant difference (49,53-57). One study reported that the predicting methods underestimated REE (58) and another study (59) reported that the predicted REE overestimated the measured REE.

When dealing with the question whether REE is affected by disease activity, several studies reported no difference in REE between patients with active or inactive disease $(54,55,57,59)$, whereas 1 study reported an increase in REE during active disease (49). REE is influenced by body size and composition; therefore, measurements of REE will differ and results depend on the method by which this was adjusted to body size and composition.

Several studies measured changes in resting energy expenditure following therapy with anti-tumour necrosis factor alpha (TNF) (infliximab) $(55,60,61)$. No differences were found in REE before and after anti-TNF therapy.

In summary, pediatric patients with IBD seem to have similar requirements as healthy children. Nevertheless, subjects should be monitored carefully for adequate and sufficient energy intake by clinical dietitian. In order to measure REE in clinical practice, the predicted equations are sufficient and indirect calorimetry may be performed only in subjects who do not gain weight sufficiently despite adequate nutrition and disease control. 


\section{Is there increased protein requirement in pediatric} IBD?

\section{Statement:}

- Protein requirement for children with IBD in remission is similar to the requirement for healthy population. During active disease protein, however, requirement may be increased (EL 4).

\section{Practice point:}

- During active disease with poor nutritional state, weight loss or growth retardation, it may be recommended to increase protein intake by at least $25 \%$ initially, or until linear growth has improved.

There are few studies that investigated this question in children with IBD; several of them tested the effect of therapy on protein metabolism. There is an increase in protein turnover in children with IBD as reported by Thomas et al (62); they demonstrated that this increase may be reduced after induction of remission with corticosteroid therapy or an elemental diet. In addition, whole body protein breakdown increased significantly after 2 weeks of corticosteroid therapy in children with newly diagnosed CD (63). Chronic inflammation or corticosteroid therapy, however, was not found to be associated with alteration in protein metabolism as reported by Motil et al (64).

Varille et al (49) presented a significant decrease in protein breakdown after surgical resection of gut lesions in children with mildly active CD. In addition, Steiner et al (63) reported a significant reduction in proteolysis and protein synthesis in the fasting and parenterally fed state following the initial infusion of Infliximab.

We would recommend increasing protein intake during flares above the recommendations for the healthy population for several reasons: children are growing, during flares children often reduce their food intake, and during inflammation there is protein loss. During remission the protein requirements for patients with IBD may, however, be as for the healthy population according to dietary reference intake (DRI)/RDA recommendations.

Is there increased carbohydrate and fat requirement in pediatric IBD?

There are no studies that demonstrate a difference in carbohydrates and fat requirements in pediatric patients with IBD compared to healthy people. A minimum consumption of carbohydrate should provide $45 \%$ to $60 \%$ of total energy consumption per day. In order to meet fat requirements, different percentages of total daily energy should be from fat based on different children's ages (Table 1).

Is there a difference in fat type requirements in pediatric IBD?

Type of fat seems to influence IBD in animal models; diets rich in fat and sugar cause alterations in the microbiome, affect the integrity of the mucus layer and increase intestinal permeability (65). Animal fat increased intestinal permeability in animal models (66). There are, however, no human studies to investigate the influence of consumption of different types of food on IBD patients except for studies investigating supplementation with omega 3 for induction and maintenance of remission in IBD patients. The data in this field do not support routine use of omega 3 and therefore, the

\begin{tabular}{lcc}
\hline TABLE 1. Estimated energy requirements & \\
\hline $\begin{array}{l}\text { Male and female } \\
4-18 \text { years }\end{array}$ & $\begin{array}{c}\text { Percentage of total } \\
\text { calories per day }\end{array}$ & RDA/AI \\
\hline Protein & $10 \%-30 \%$ & $\begin{array}{c}\text { Varies on the basis } \\
\text { of age and gender }\end{array}$ \\
Carbohydrate & $45 \%-60 \%$ & ND \\
Fat & $40 \% 6-12$ months; & ND \\
& $35 \%-40 \% 1-3$ years; & \\
& $20 \%-25 \%>4$ years & \\
\hline
\end{tabular}

Based on the following European Food Security authority (EFSA) recommendations:

1. https://www.efsa.europa.eu/it/efsajournal/pub/2557.

2. https://www.efsa.europa.eu/it/efsajournal/pub/1462.

3. https://www.efsa.europa.eu/it/efsajournal/pub/1461.

$\mathrm{AI}=$ adequate intake; $\mathrm{RDA}=$ recommended daily allowance

recommendations for IBD patients are the same as for the healthy population $(67,68)$.

\section{TRACE ELEMENTS, MINERALS, AND VITAMINS}

\section{Trace Elements (Zinc, Selenium)}

What is the risk for deficiencies of trace elements in children with IBD and should these be monitored?

\section{Statement:}

- Due to insufficient data, we do not recommend routine measurement or supplementation of zinc and selenium in children with IBD (EL 2).

\section{Practice points:}

- Clinically significant deficiency of zinc is uncommon in children with IBD. It seems prudent to assess zinc status during prolonged diarrheal episodes ( $>4$ weeks).

- When zinc deficiency is encountered, a short course (2-4 weeks) of oral zinc is usually sufficient to restore adequate serum levels.

\section{Zinc}

Small cohorts of children with IBD yielded up to $40 \%$ zinc deficiency, particularly in children with CD (69-71). Serum zinc levels were shown to be significantly lower in pediatric $C D$ patients compared with healthy controls (72). Zinc consumption was reported to be inadequate in up to $15 \%$ of children with IBD (73). A daily oral supplement of 20 to $40 \mathrm{mg}$ elemental zinc (for 2-3 weeks) was suggested for patients with significant diarrhea (>300 g of stool/day) (74).

\section{Selenium}

Only a few studies reported significantly low mean selenium levels, irrespective of disease activity and/or location, in both adult UC and CD patients, compared with controls (75-79). Two small pediatric cohort studies yielded contradictory results $(72,80)$. 


\section{Minerals (Iron, Magnesium, Calcium)}

What is the most effective and safe treatment option of pediatric IBD-associated iron deficiency anemia (IDA)?

What is the risk for deficiencies of other minerals in children with IBD and should these be monitored?

\section{Statements:}

- Iron supplementation is recommended in all pediatric IBD patients when IDA is present, to normalize hemoglobin level and iron stores (EL 2).

- Oral iron supplementation is effective in IDA IBD patients with mild ( $>10 \mathrm{~g} / \mathrm{dL})$ anemia and negative inflammatory markers (EL 4).

- Intravenous (IV) iron supplementation is the preferred method of supplementation for pediatric patients with clinically active IBD (EL 4).

- Children with IBD should be monitored for recurrence of iron deficiency (ID) as this may indicate persistent intestinal disease activity (EL 2).

- Due to insufficient data, we do not recommend routine measurement or supplementation of magnesium in children with IBD (EL 2).

- Measuring magnesium levels should be considered in children with prolonged diarrhea ( $>4$ weeks) and those at risk of refeeding syndrome (EL 4).

- Calcium intake should be monitored in children and adolescents with IBD and low calcium intake should be supplemented (EL 2).

\section{Practice points:}

- Oral iron replacement is associated with high levels of intolerance and consequent lack of adherence.

- IV ferric carboxymaltose supplementation is better tolerated and superior to oral treatment, particularly in active IBD with low hemoglobin $<10 \mathrm{~g} / \mathrm{dL}$.

- When magnesium deficiency is encountered, a short course (2-4 weeks) of oral magnesium is usually sufficient to restore adequate serum levels.

- Due to insufficient evidence, we do not recommend a specific dose for calcium supplementation, but suggest following the European Food Safety Authority (EFSA) recommendations for the general pediatric population (ie, $450 \mathrm{mg}$ calcium from age $1-3$ years, $800 \mathrm{mg}$ from age $4-8$ years, $1150 \mathrm{mg}$ from age $9-18$ years).

- Due to insufficient evidences the screening of bone mass density trough dual-energy $\mathrm{x}$-ray absorptiometry (DXA) should not differ from the general population and it should be only recommended in those children at higher risk of osteoporosis.

\section{Iron}

ID, IDA, and anemia of chronic disease (ACD), recently defined by ECCO guidelines are common in pediatric IBD (81-83). Expectant management of IBD-associated anemia is associated with persistence of the anemia, well beyond induction of remission, in up to $50 \%$ of patients $(84,85)$. The impact of ACD/IDA, which may co-exist, and even ID on the quality of life (QoL) of IBD patients, is considerable $(83,86,87)$. Inflammatory cytokines affect the hepcidin-ferroportin axis, which leads to reduced duodenal iron absorption, while also reducing erythropoietin production contribute to the anemia in IBD patients (88-92). Due to the existence of specific ECCO guidelines, this paper will not discuss in details all markers of ID (83).

Oral iron can be delivered in various formulations (93). Oral iron replacement is often associated with intolerance (nausea, abdominal pain, and constipation) and consequent lack of adherence $(85,94,95)$. Oral iron therapy may enhance intestinal inflammation and has been shown to alter the intestinal microbiome (9698). Recently, Rampton et al (99), have, however, shown that oral iron supplementation did not increase disease activity during a 6week open study.

The first generation of IV iron products (high molecular weight iron dextran) was associated with serious anaphylactic reactions and should no longer be used $(93,100,101)$. The second generation of IV iron products (such as iron sucrose and ferric carboxymaltose) appears to have better safety profiles (93$95,102-106)$. In 2 retrospective reports of pediatric IBD patients receiving either iron sucrose infusions $(n=75)$ or ferric carboxymaltose $(n=72)$, there were only minor adverse reactions $(20 \%$ and $4 \%$, respectively) with no serious adverse events $(102,107)$. Hemoglobin level significantly improved following 4 infusions of iron sucrose. Although there are no studies in pediatric IBD directly comparing oral versus IV iron supplementation, adult IBD studies have shown the IV route to be better tolerated and superior, particularly in active IBD with low hemoglobin $<10 \mathrm{~g} / \mathrm{dL}$ $(95,108)$.

\section{Magnesium}

Few studies demonstrated substantial rates of magnesium deficiency in adult IBD patients $(109,110)$ ranging from $13 \%$ to $88 \%$, whereas a single pediatric study reported a low magnesium intake relative to the RDA (EFSA RDA: $80 \mathrm{mg}$ /day for age 7-11 months, $170 \mathrm{mg} /$ day for age $1-3$ years, $230 \mathrm{mg} /$ day for age $3-10$ years, $300 \mathrm{mg}$ /day for boys and $250 \mathrm{mg}$ /day for girls for age $10-18$ years) (7).

\section{Calcium}

Many patients with IBD have a low dairy calcium intake $(73,111)$. In adults, the effect of calcium (and vitamin D) supplementation on bone mineral density (BMD) is controversial (112). In children with IBD, an open-label, prospective study about the effect of calcium and vitamin $D$ supplementation on BMD suggested that supplementation of calcium and vitamin D does not improve BMD (113). Nevertheless, it is well-known that patients with IBD have an increased risk of reduced BMD (114117). It has been reported that children with IBD have low BMD, with almost $50 \%$ having BMD $z$ scores $<-1$ SD and around $25 \%$ having BMD $z$ scores $<-2$ SD, regardless of sex $(114-116,118)$. Numerous factors have been implicated in suboptimal bone mineralization, including chronic systemic inflammation, malnutrition, corticosteroid treatment, delayed puberty, growth retardation, low BMI, and a sedentary lifestyle $(119,120)$. The diagnosis of osteoporosis in adults is based on assessment of BMD by DXA. In young adults, osteoporosis is defined as a BMD value at least 2.5 standard deviations lower than the mean BMD for young healthy adults ( $\mathrm{t}$ score $\leq-2.5$ ) (121). In children, the relationship between BMD and fracture risk is not well established and reference to the $z$ score has been recommended. A $z$ score $<-2$ should be reported as "below 
expected range for age'" and the need for treatment interpreted in the context of fracture risk factors (122). In the absence of further evidences, screening recommendations for DXA in children with IBD should not differ from the general population and should be limited to those patients at higher risk, such as long-term use of corticosteroids.

\section{Fat-soluble Vitamins}

Do children with IBD have a risk for vitamin D deficiency?

What is the best option to treat vitamin D deficiency?

Can vitamin D and/or calcium supplementation improve BMD?

What is the risk for deficiencies of fat-soluble vitamins in children with IBD and should these be monitored?

\section{Statements:}

- We recommend monitoring vitamin $\mathrm{D}$ levels in all children with IBD (EL 2).

- Vitamin D supplementation is recommended in children with IBD when vitamin D deficiency is present (ie, $25(\mathrm{OH})$ D concentrations below $50 \mathrm{nmol} / \mathrm{L}$ or $20 \mathrm{ng} / \mathrm{mL}$ ) (EL 3).

- Due to insufficient data, we do not recommend routine measurement or supplementation of vitamins $A, E$, and $K$ in the absence of chronic liver disease (EL 2).

\section{Practice points:}

- A serum 25(OH) D concentration above $50 \mathrm{nmol} / \mathrm{L}$ or $20 \mathrm{ng} / \mathrm{mL}$ indicates sufficiency, whereas serum concentration below $25 \mathrm{nmol} / \mathrm{L}$ or $10 \mathrm{ng} / \mathrm{mL}$ suggests severe vitamin $D$ deficiency.

- A standard weight-based dose for replenishment of vitamin D in children with IBD has not been yet established. Evidence implies that high doses (ie, $\geq 2000$ IU daily or 50,000 IU weekly) and longterm treatment may, however, be necessary to maintain sufficiency.

\section{Vitamin D}

The main function of vitamin $\mathrm{D}$ is the regulation of calcium and phosphate. It is essential for bone health but also has an important role in immune regulation. In infants and children, a serum $25(\mathrm{OH})$ vitamin $\mathrm{D}$ concentration $>50 \mathrm{nmol} / \mathrm{L}$ or $20 \mathrm{ng} / \mathrm{mL}$ indicates sufficiency $(123,124)$. There is, however, insufficient evidence demonstrating that vitamin $\mathrm{D}$ supplementation provide measurable health benefits other than providing adequate blood levels (125).

Several studies in adult IBD patients including a metaanalysis reported that patients with IBD had lower serum $25(\mathrm{OH}) \mathrm{D}$ concentrations compared with healthy controls with an inverse correlation to disease severity (126-129). A retrospective case-controlled study observed no difference in $25(\mathrm{OH}) \mathrm{D}$ levels between children with IBD and healthy controls (130). In contrast, 2 pediatric studies reported that serum level of $25(\mathrm{OH}) \mathrm{D}$ were significantly lower in children with IBD compared to a controls with no correlation to either BMD (131) or to disease activity (132). Predisposing factors included dark skin, winter season, and more severe disease. Pediatric studies observed a $19 \%$ to $35 \%$ rate of vitamin deficiency in children with IBD, associated with greater corticosteroid exposure (133). The question remains as to whether vitamin D deficiency is truly a cause or effect of IBD activity in humans.

Two pediatric IBD randomized controlled trials (RCTs) have not found significant differences in the effect of different oral doses of vitamin D ranging from 400 IU to 2000 IU daily $(134,135)$ whereas 1 RCT did show benefit for higher range doses (either 2000 IU daily or $50,000 \mathrm{IU}$ weekly)(136). A recent trial demonstrated a significant though short-term effect of either $10,000 \mathrm{IU}$ or $5000 \mathrm{IU}$ per $10 \mathrm{~kg}$ body weight per week for 6 weeks (137). Regular supplementation of 2000 IU daily or 50,000 IU weekly was, however, successful in replacing deficiency in the long term (71). A single age-based highdose oral cholecalciferol (Stoss) sustained sufficient vitamin D levels for at least 6 months (138).

Supplementation with daily calcium and vitamin D was associated with BMD increment in adult IBD patients (139). An open-label, prospective study in children with IBD, however, suggested that supplementation of calcium and vitamin D does not affect BMD (114).

\section{Vitamin A}

Vitamin A (measured as retinol or $\beta$-carotene levels) was shown to be variably low in adult IBD patients $(7,140-142)$. The DRI for daily vitamin A consumption was not met in 36\% to $90 \%$ of IBD patients. Vitamin A deficiency was found in 14\% of 97 children with IBD and was associated with increased disease activity (143).

\section{Vitamin $E$}

Of the few adult studies assessing vitamin $\mathrm{E}$ status in IBD patients $(142,144,145)$ only 1 found a significantly lower serum level in CD patients. Two small pediatric cohorts did not demonstrate significant difference in vitamin $\mathrm{E}$ levels between IBD patients and controls $(70,112)$. A single pediatric study demonstrated overall deficiency of $6 \%$, which increased to $40 \%$ of those with moderately to severely disease (143).

\section{Vitamin $K$}

Vitamin K deficiency has been scarcely reported in adult patients with IBD (more commonly in CD) with a weak correlation to active disease (146-148). In adult CD patients, low levels of free and bone-vitamin $\mathrm{K}$ were found to be associated with low BMD (147). In a recent pediatric study, the prevalence of vitamin $\mathrm{K}$ deficiency was $54.0 \%$ in CD and $43.7 \%$ in UC and correlated with disease activity (149).

\section{Water-soluble Vitamins}

What is the risk for deficiencies of water-soluble vitamins in children with IBD and should these be monitored?

What is the recommended supplementation of folic acid in children with IBD receiving methotrexate (MTX)?

When should vitamin B12 level be monitored in children with IBD and how vitamin B12 should be supplemented in the case of deficiency? 


\section{Statements:}

- We recommend monitoring folic acid annually (EL 2).

- We do not recommend routine measurement or supplementation of vitamin B1, B2, B3, B6, B7 and vitamin $C$ in children with IBD (EL 2).

- We recommend folic acid supplementation (either $1 \mathrm{mg}$ daily or $5 \mathrm{mg}$ weekly) in children with IBD receiving MTX therapy ( $E L$ 2).

- We recommend that either serum cobalamin levels or methylmalonic acid level in blood or urine should be measured in children with active ileal $C D$, children with ileal resection of $>20 \mathrm{~cm}$ and $U C$ children ileal pouch surgery at least annually (EL 4).

- We recommend that vitamin B12 supplementation is given intramuscularly for pediatric IBD patients with evidence of vitamin B12 deficiency (EL 2).

\section{Practice points:}

- Clinically significant deficiency of folate is uncommon in children with IBD. Nevertheless, considered the increased risk when compared to the healthy children, we suggest to measure either serum folate level or folate level in red blood cells (RBCs) at least annually, or if macrocytosis is present in the absence of thiopurine use.

- Folate supplementation of $1 \mathrm{mg} /$ day is usually sufficient to replenish deficient folate stores within 2 to 3 weeks; however, the folic acid requirement of children with $C D$ has not been determined.

- CD patients with terminal ileal resection of $>20 \mathrm{~cm}$ have the greatest risk for vitamin B12 deficiency. Patients with distal ileal resection of $>60 \mathrm{~cm}$ will require lifelong B12 supplementation.

- Patients with extensive distal ileal resection or with clinical deficiency of vitamin B12 should receive $1000 \mu \mathrm{g}$ of injected B12 every other day for 1 week and then weekly until clinically improved, followed by periodic injections according to methylmalonic levels.

\section{Vitamin C}

Hypovitaminosis $\mathrm{C}$ is not uncommon in adult IBD patients and appears to be equally common in patients with $\mathrm{UC}$ or $\mathrm{CD}$ regardless of disease activity $(112,141,150)$.

\section{Vitamin B1}

Thiamine deficiency was shown to be more common in CD patients compared with controls even when disease is in remission $(7,151)$. High-dose oral thiamine in IBD patients was shown to improve fatigue symptoms in an open-label pilot study (141). This observation calls for well conducted studies and the authors suggestion that, high dose may enhance cellular transport thus affecting fatigue, needs to be examined.

\section{Vitamin B2}

Riboflavin deficiency does not appear to be common in IBD, with only few studies reporting a relative low intake of riboflavin in adults $(71,150,152)$ and in children $(7,153)$.

\section{Vitamin B3}

A single study found that $77 \%$ of adult CD patients have low plasma vitamin B3 during remission (112).

\section{Vitamin B6}

Two studies reported $10 \%$ to $13 \%$ rates of vitamin B6 deficiency in adult IBD patients $(145,154)$. Low intake of B6 was reported in children with IBD (155).

\section{Vitamin B7}

Two studies yielded contradictory results regarding of biotin status in IBD patients $(145,150)$.

\section{Folate (B9)}

Folate levels can be measured in serum or more accurately in $\mathrm{RBC}$ and also by measuring serum homocysteine levels. Several adult studies showed that folate deficiency ranges from $20 \%$ to $30 \%$ in CD patients and $4 \%$ to $10 \%$ in UC patients, particularly in patients with active ileitis or history of small bowel resection (155-157). A study using RBC folate levels, however, yielded much lower rates of deficiency $(0 \%-7 \%)(73)$. Studies in children are more controversial with results ranging from low (158) through normal $(70,71)$ and even high serum folate levels $(159,160)$.

Both sulfasalazine and MTX can cause folate deficiency, as both are inhibitors of dihydrofolate reductase and cellular uptake of folate (125). A recent systematic review showed that folic acid supplementation in MTX-treated patients with rheumatoid arthritis reduces the incidence of abnormal liver function tests, gastrointestinal (GI) adverse effects, and rates of withdrawal from treatment (161). The optimal dosage of supplementation has not been established though either a daily dose of $1 \mathrm{mg}$ or a weekly dose of $5 \mathrm{mg}$ seem to be sufficient (162). ECCO guidelines recommend measuring folate level at least annually, or if macrocytosis is present in the absence of thiopurine use (83). Folate supplementation of $1 \mathrm{mg} /$ day is usually sufficient to replenish deficient folate stores within 2 to 3 weeks (163).

\section{Vitamin B12}

Vitamin B12 status is measured by either serum B12 levels or more accurately by methylmalonic acid and homocysteine levels (164). The causes of vitamin B12 deficiency in patients with IBD include ileal disease or resection, fistulas, small bowel bacterial overgrowth and reduced intake $(165,166)$. A systematic review, including 3732 patients, concluded that B12 deficiency in patients with UC or with CD with no ileal resection (or resection of $<20 \mathrm{~cm}$ ) is no more common than in the general population (165). Using methylmalonic acid levels B12 deficiency, however, increased to $32 \%$ and was associated with active terminal ileitis (167). Vitamin B12 deficiency was also demonstrated in UC patients with ileoanal pouch (168). Pediatric data are scarce with 2 small cohorts yielding contradictive results $(70,169)$. Previous studies demonstrated that patients with terminal ileal resections of $>60 \mathrm{~cm}$ will need lifelong B12 replacement (169), whereas up to $48 \%$ of patients with resection of 20 to $40 \mathrm{~cm}$ are at risk of eventually developing B12 deficiency (170). 
ECCO guidelines recommend assessing cobalamin level at least annually or when macrocytosis is present, in the absence of thiopurine use (83). Vitamin B12 status should be assessed in patients with active ileal CD or history of ileal resection $(>20 \mathrm{~cm})$, although the recommended intervals for screening have not been established (165). Patients with clinical deficiency should be treated with scheduled intra-muscular injections (171).

\section{NUTRITION AS A PRIMARY THERAPY IN INFLAMMATORY BOWEL DISEASE}

\section{Parenteral Nutrition}

How efficient is parenteral nutrition (PN) induction of remission in children with IBD?

\section{Statement:}

- PN should not be used as means to induce remission in pediatric CD (EL 4).

\section{Practice points:}

- PN should only be used when oral nutrition support or enteral support is insufficient to meet the patients' requirements or when enteral feeding is contraindicated.

- In selected cases, when enteral nutrition (EN) cannot be used, PN may have a role as a support therapy within the preoperative period in children undergoing elective surgery.

- $\mathrm{PN}$ is more expensive and raises safety concerns in comparison to EEN.

\section{Indications for $\mathrm{PN}$ in pediatric patients with IBD}

Chronic intestinal failure necessitating the need for home PN is uncommon in $\mathrm{CD}$ and is observed mainly in adults due to resections of a significant portion of the small intestine (172). In the largest cohort of home PN published recently, of 251 pediatric patients on home PN, 9 had CD and 4 had UC (173). If intestinal failure occurs and when EN is contraindicated (hemodynamic instability, intestinal ischemia, intestinal obstruction, ileus, severe intestinal hemorrhage, and high-output fistulae), the individual nutrition goals should, however, be met by the provision of PN. Preferably, this should be limited to a short period (few weeks); however, in cases of intestinal failure this may need to be done indefinitely.

Should PN be used to induce remission in children with IBD? In 1 study, EN was as good as PN for induction of remission and the probability to remain in remission after 1 year (174). In another study, elemental diet and PN were equally as effective in remission induction (175).

Overall, PN only has a role in children with or at risk of malnutrition and in children in need of nutrition support where the use of EN is contraindicated or is insufficient to maintain nutritional status and growth. Although it was never adequately studied in children, clinical wisdom as well as costs and safety concerns, however, should limit the use of PN to its classical roles as stated above.

\section{EXCLUSIVE ENTERAL NUTRITION}

What is the efficacy of EEN for the induction of remission of pediatric CD?

\section{Statements:}

- EEN has the same efficacy as oral steroids in the induction of remission of children with active luminal CD (EL 1).

- EEN may be re-used during the course of disease in case of relapse (EL 2).

Although no placebo-controlled RCT of EEN have been conducted, several RCTs summarized in 3 different meta-analyses, established the efficacy of EEN for the induction of remission in children with CD (176-178). As stated in the most recent guidelines on the therapeutic management of pediatric CD (45), the overall combined remission rate for $\mathrm{EEN}$ is $73 \%$ (relative risk $0.95,95 \%$ confidence interval $0.67-1.34$ (177) and relative risk $0.97,95 \%$ confidence interval 0.7-1.4 (178). After the publication of the last meta-analysis, 1 RCT and some other prospective studies were published replicating the previous results (179-182). The overall conclusion is that EEN has the same efficacy in the induction of remission as corticosteroids. Recently, the efficacy of EEN has been confirmed in comparison to biological therapy. Lee et al (183) enrolled 90 consecutive children with an active $C D$ in a prospective study. Patients received EEN, infliximab or partial enteral nutrition (PEN) as therapy for induction of remission. Clinical response was achieved in $88 \%$ of children treated with EEN, $84 \%$ of those receiving biological therapy and 64\% in children undergoing PEN (183).

In conclusion, considering all the benefits of EEN and taking into account the adverse effects of steroids, EEN should be considered as the first-line therapy to induce remission in pediatric luminal CD (45).

Few retrospective studies evaluated the efficacy of a second course of EEN as induction therapy during the course of the disease. Remission rates ranged from $58.3 \%$ to $80 \%$ (184-187). In the most recent retrospective study including 52 children, Frivolt et al (187) reported a $92 \%$ of remission rate after the first cycle of EEN and $77 \%$ after a second cycle of EEN, although a second cycle was used in only 26 children. These data confirm that if the compliance of the patients is maintained, EEN may be successfully reused during the subsequent course of the disease for future relapses.

\section{Type of Formula and Delivery Mode}

\section{Statement:}

- The use of standard polymeric formula, with a moderate fat content, is recommended unless other conditions are present (eg, cow's milk protein allergy) (EL 1).

\section{Practice points:}

- There is no evidence that the dietary source of proteins affects the efficacy of EEN.

- Initially the formula should be administered orally. A nasogastric tube may be used when there is failure to achieve adequate oral intake. 
The source of proteins seems not to affect the efficacy of EEN. Indeed, numerous studies have compared the efficacy of different types (elemental, semi-elemental, oligomeric, or polymeric diets) of enteral formulas in the management of active CD with no significant results (188-190). This was further confirmed by a Cochrane meta-analysis of 10 trials showing no statistically significant difference between patients treated with elemental and non-elemental diet (191). Therefore, unless cow's milk protein allergy co-exists, polymeric formula should be preferred considering the better palatability and the lower costs (192). Given the pro-inflammatory properties of some lipids, fats' composition of formulas has been postulated as one of the possible mechanism to explain EEN efficacy. Although, no studies have been published in pediatrics, 2 adults' trials demonstrated no differences when increasing medium-chain triglycerides (193) or monounsaturated fatty acids content in the formulas (194). Similarly, a subanalysis of a Cochrane demonstrated no differences in induction of remission of CD between low-fat and high-fat formulas (48). Finally, the addition of metabolites with antiinflammatory properties such as glutamine (68) or omega-3 $(116,117)$ has not given positive results and should not be recommended.

To date, few formulas with the adequate caloric intake are available and successfully used for delivering EEN in children. No comparison study in terms of effectiveness has, however, been performed so far.

No differences in term of efficacy have been observed between oral EEN and continuous administration through a nasogastric tube (181). Considering that the use of a nasogastric tube may decrease the improvement of QoL achieved with EEN (195), oral feeds should be preferred. A nasogastric tube should be positioned if adequate caloric intake could not be achieved orally (45).

Duration and Reintroduction of Foods

\section{Statement:}

- EEN is recommended for a period of at least 8 weeks (EL 1).

\section{Practice point:}

- There is still insufficient evidence to recommend a standard food reintroduction scheme. In the absence of evidence we suggest a gradual reintroduction of the foods, with a concomitant reduction of the formula over a 2- to 3-week period.

There is no evidence regarding the precise duration of EEN. Duration of EEN in clinical studies varied from 2 to 12 weeks, with majority using 6 to 8 weeks (196). Symptoms usually improve after a few days on EEN and mucosal healing was demonstrated after 8 weeks (197). In accordance with the last CD guidelines we suggest that EEN induction therapy should last at least 6 weeks (45).

There is no evidence to guide reintroduction of normal food after the EEN. Recently, Faiman et al (198) conducted a retrospective study comparing a standard food reintroduction over 5 weeks versus a rapid reintroduction over 3 days. No significant differences were observed in terms of relapse rate and maintenance of remission over 1 year. The authors concluded that due the better tolerability, a rapid reintroduction should be preferred (198). This study, however, suffers several limiting factors; it was retrospective and had high drop-out ( 20 of 31 children with slow introduction and 19 of 33 were included in the analysis). In the absence of more solid evidences, a gradual food reintroduction with concomitant decrease of formula volume over a 2- to 3-week period, as suggested in CD guidelines (45), should still be the preferred approach.

\section{Location and Behavior of Disease}

\section{Statement:}

- EEN should be recommended in all cases of active luminal disease irrespective of the GI tract location (EL 2).

\section{Practice point:}

- There is insufficient evidence to recommend EEN for isolated oral or perianal disease and for extraintestinal manifestations.

Opposing data exist regarding the efficacy of EEN and CD disease location. Previous studies $(197,199)$ suggested a better efficacy of EEN in patients with ileal involvement compared to isolated colonic disease. More recent data, however, demonstrated no significant differences between isolated colonic disease and small bowel CD $(181,184)$. Particularly, in the retrospective study from Rubio et al (181), which included 106 CD patients, no significant difference was observed regarding location of disease. Conversely, another retrospective analysis including 114 children reported that individuals with isolated terminal ileal disease $(n=4)$ had lower remission rates than other locations $(P=0.02)(180)$. In the absence of better scientific evidence, these data support the conclusions of the Cochrane meta-analysis, which suggested the use of EEN in all pediatric $C D$ patients with luminal disease, irrespective of the disease location (176).

To date there are no data to support the use of EEN in patients with isolated extraintestinal manifestations or oral disease. Efficacy of EEN for active perianal disease was reported only in a small case series (200).

\section{Adverse Effects}

\section{Practice points:}

- Clinicians should be aware of the risk of refeeding syndrome in severely malnourished children.

- Other possible adverse effects include nausea/vomiting, diarrhea, abdominal discomfort, bloating.

EEN is associated with minimal and temporary adverse effects. Most common reported are nausea, diarrhea, constipation, abdominal pain, and bloating (201). Borrelli et al (202) reported that 4 of 17 patients $(23.5 \%)$ had mild GI adverse effects. The only severe reported adverse event was refeeding syndrome. Refeeding syndrome is defined as a potentially fatal metabolic complication causing shifts in fluids and electrolytes (especially hypophosphatemia) that may occur in severely 
malnourished patients after the start of refeeding (203). Refeeding syndrome has been described in 3 case reports in malnourished CD children $(204,205)$. Therefore, the awareness of a clinician for this life-threatening complication is essential, because the risk of refeeding syndrome can be dramatically decreased by a slow increase of EEN (volume and concentration) over several days, starting with reduced caloric intake (last known intake or $50 \%-75 \%$ of the REE and advancing only when there are no significant electrolyte abnormalities.

What is the efficacy of EEN for the maintenance of remission of pediatric CD?

\section{Statement:}

- There is no evidence for using EEN as a maintenance therapy (EL 4).

\section{Practice points:}

- Due to the highly demanding adherence, EEN should not be considered as an option for longterm maintenance therapy.

No study has evaluated the role of EEN for the maintenance of remission in children with CD. Due to the low compliance of patients after the induction cycle, we do not recommend EEN for the maintenance of remission in children with CD.

What is the efficacy of EEN for the induction and maintenance of remission of pediatric $\mathrm{UC}$ ?

\section{Statement:}

- EEN is not efficacious in the induction and maintenance of remission of pediatric UC (EL 4).

What is the efficacy of EEN on mucosal healing of pediatric CD?

\section{Statements:}

- EEN promotes mucosal healing (EL 2).

- EEN also promotes transmural healing in a proportion of patients.

Effect of EEN on mucosal healing was investigated by 7 studies $(181,195,197,202,206-208)$ where endoscopy was performed 8 or 10 weeks after initiation of EEN. All studies found improvement in mucosal inflammation and complete mucosal healing was found in $19 \%$ to $87 \%$ of patients. Two studies, 1 open-label RCT (202) and other retrospective study (208) compared mucosal healing between children treated with corticosteroids and with EEN. Both studies found significantly higher rate of mucosal improvement in EEN group (42\% vs $87 \%$ and 0 vs $19 \%$ ). Furthermore, there is evidence that early endoscopic response is associated with reduced relapses, hospitalization and need for antiTNF treatment at 1 year of follow-up (207). In 3 of $14(21 \%)$ children EEN was even able to induce complete transmural remission of ileal CD (207).

\section{What are the long-term outcomes of EEN?}

\section{Statements:}

- EEN improves nutritional status (EL 2) and QoL (EL 3).

- There is insufficient evidence at present to show that EEN improves long-term bone health (EL 4).

a) Remission duration

Remission duration after EEN is not well determined. Overall 11 studies $(179,185-187,192,197,198,208-211)$ reported relapse rate in the longer period (10 months to 7 years). Relapse rate ranged from $42 \%$ to $67 \%$ in the first year $(187,192,198,209,211)$ and $58 \%$ to $68 \%$ at 24 months $(179,186,211)$. Median time to first relapse ranged from 6.5 to 12.7 months $(185-187)$. Duration of remission after induction with EEN versus corticosteroids was assessed by 3 studies and results were contradictory. Thomas et al (210) found shorter remission duration after EEN, but 2 more recent studies found longer duration of remission if EEN was used as a first-line induction therapy $(208,209)$. Furthermore, although it did not report difference in remission duration after EEN or corticosteroids, 1 study reported protection against relapses in EEN group during the 24 months period (211). These results, however, should be interpreted with caution due to their retrospective nature and high possibility of other confounding factors.

b) Growth and bone health

All studies investigating weight change during EEN treatment reported positive effect of EEN on weight. Three studies showed an increase in lean body mass $(53,212,213)$. Results on height increase are conflicting. Some studies reported height velocity increased immediately after the EEN treatment $(202,207,208,214)$. Furthermore, there is no agreement on long-term results; retrospective studies with no comparative cohort found no significant long-term improvement in height $z$ score (185-187); studies which compared EEN and corticosteroids found conflicting results: 2 studies $(210,215)$ found better growth rate if EEN was used as a primary induction therapy and one showed no difference (216).

The influence of EEN on bone health has been investigated by 3 studies $(213,216,217)$. Werkstetter et al (213) prospectively evaluated data on bone quality using peripheral quantitative computed tomography and found improved bone metabolism within 3 months of starting EEN with no further normalization afterwards (1 year of follow-up). EEN therapy also normalized markers of bone turnover 8 weeks after EEN introduction (217). After a follow up of 1 year EEN group had a nonsignificant improvement in BMD assessed by DXA (216).

c) Quality of life

Two studies evaluated QoL after the treatment with EEN both showing improvement in QoL scores after EEN $(183,195)$. Additionally, patients who received EEN comparing to partial $\mathrm{EN}$ and anti-TNF therapy had similar improvement in QoL scores (determined by IMPACT score) (183). 


\section{PARTIAL ENTERAL NUTRITION}

\section{Definition}

PEN is defined as providing subjects with a nutritionally balanced liquid formula while continuing to eat an unrestricted or exclusion diet.

What is the efficacy of PEN for the induction of remission of pediatric CD?

\section{Statement:}

- PEN alone should not be used for induction of remission (EL 2).

\section{Practice points:}

- PEN alone is not efficacious to induce remission in the majority of patients.

- Supplementation with a standard polymeric formula, in addition to conventional induction treatment may be considered.

Johnson et al (218) showed in an RCT the superiority of EEN over PEN in clinical remission rates defined using the Pediatric Crohn's Disease Activity Index (PCDAI) as the primary outcome measure at 6 weeks $(10 / 24$ [42\%] vs 4/26 [15\%], respectively, $P=0.03)$. In this study, PEN provided an average of $47 \%$ of total energy requirements (range $39 \%-58 \%$ ).

Additionally, a recent prospective study of children initiating PEN, EEN, or anti-TNF therapy for active CD, confirmed that each therapy improved symptoms, but EEN and anti-TNF therapies were significantly superior to PEN providing between $80 \%$ and $90 \%$ of estimated calories needed for inducing mucosal healing (183). In a retrospective cohort of 28 children with $\mathrm{CD}$, supplementation with polymeric formula, additionally in conventional treatment, was associated with a decrease in PCDAI, whereas children who were not on supplementation did not (219). Gupta et al (220) administered formula overnight to deliver $80 \%$ to $90 \%$ of overall needs with the remaining $10 \%$ to $20 \%$ of their caloric needs came from an unrestricted diet of small meals or snacks during the day. This was effective for the induction of remission in pediatric patients with CD. More recently, Sigall-Boneh et al (221) proposed a dietary intervention in mild-to moderate $\mathrm{CD}$, based on $50 \%$ PEN and a structured exclusion diet, which led to remission in $70 \%$ of children.

What is the efficacy of PEN for the maintenance of remission of pediatric CD?

\section{Statement:}

- PEN is a treatment option to maintain remission in selected patients with mild disease and low risk of relapse (EL 4).

What is the optimal daily amount and recommended duration of PEN for the maintenance of remission of pediatric CD?

\section{Statement:}

- The optimal daily amount and the duration of PEN that needs to be consumed to be effective are unknown (EL 4).

\section{Practice points:}

- A long- or short-term PEN course, in addition to unrestricted normal or specific food diet may be offered in order to prolong the period of remission in patients who are on no other maintenance treatment for $C D$.

Long-term enteral nutritional supplementation, in addition to unrestricted normal or specific food diet, such as low-fat diet, may prolong the period of remission and reduce relapse rates in patients with $\mathrm{CD}$. There is limited research evidence relating to maintenance $\mathrm{EN}$ as a treatment for pediatric CD patients, with many of the best studies being performed in adults (222). Yamamoto et al (222) performed a systematic review in adult $\mathrm{CD}$, including 10 studies: 1 RCT, 3 prospective nonrandomized trials, and 6 retrospective studies. The clinical remission rate was significantly higher in patients receiving PEN in all 7 studies comparing PEN to nonsupplementation. Additionally, in 2 studies, PEN showed reduction in endoscopic disease activity. There are a smaller number of pediatric studies. Wilschanski et al (223) showed retrospectively that providing PEN (nocturnal nasogastric supplements), without restriction of normal diet, after successful treatment with EEN, was associated with prolongation of remission and improved linear growth. Duncan et al (224) demonstrated that a subgroup of patients can successfully continue PEN supplements postinduction of remission with EEN as an effective maintenance treatment and had 1 year remission rates matching thiopurines. PEN therefore seems a useful strategy in a subgroup of patients especially in those who are not commencing azathioprine or similar maintenance treatments. In contrast to the previous studies suggesting the efficacy of PEN, Knight et al (185) reported that the intake of maintenance enteral feeding was not associated with significantly decreased relapse rate.

In adult studies investigating the impact of the quantity of enteral formula on clinical remission, higher amounts of enteral formula $(35 \%-50 \%)$ were associated with higher remission rates $(225,226)$. In children the proportion of PEN varies between studies. It is clear that further studies are needed to find appropriate amount, duration, timing of PEN (185).

\section{PROBIOTICS AND PREBIOTICS IN INFLAMMATORY BOWEL DISEASE}

What is the clinical efficacy and safety of probiotics, when compared to no treatment, placebo, pharmacological treatment, or alternative nonpharmacological treatment in the induction and maintenance of remission of pediatric $\mathrm{UC}$ and $\mathrm{CD}$ ?

\section{Statements:}

- There is limited evidence in favor of using VSL\#3 or Lactobacillus reuteri ATCC 55730 as adjuvant to standard therapy for induction of remission in mild-to-moderate pediatric UC (EL 2).

- There is evidence in favor of using VSL\#3 or Escherichia coli Nissle as an alternative to 5-ASA therapy in maintenance of remission in mild-to-moderate pediatric UC especially in mesalazine (5-ASA)p intolerance (EL 2).

- VSL\#3 has shown efficacy for maintaining antibiotic-induced remission in pouchitis and for preventing it in adults (adult EL 2; pediatric EL 5). 
- We do not recommend the use of probiotics in the induction or in the maintenance of remission of pediatric CD (EL 2).

\section{Practice points:}

- Probiotics should be used with caution in patients with central venous catheter or in immunocompromised patients.

- Results from clinical trials are strain-specific and should not be extrapolated to other bacterial strains.

High-quality studies on the effect of probiotics in pediatric IBD are limited, with only 3 RCTs 2 in UC $(227,228)$ and 1 in CD (229). Some extrapolations can be made from adult data (230-241), but these have limited applicability in the pediatric population.

\section{Ulcerative Colitis}

Oliva et al (228) showed an effect on decrease of both endoscopic (Mayo score) and histological score during 8 weeks of follow-up in group of pediatric patients treated by rectal enema containing L reuteri ATCC 55730 in addition to 5-ASA treatment, but not in placebo arm in mild-to-moderate active distal pediatric UC. Miele et al (227) has shown VSL\#3 to be superior to placebo in both induction and maintenance of remission (1-year follow-up) when added to standard treatment in pediatric newly diagnosed UC.

An open-label study of VSL\#3 in induction of remission in children with mild to moderate active UC (242) and another small study on E coli Nissle showing efficacy comparable to 5-ASA in maintenance of remission in pediatric UC (not an RCT) (243) were excluded.

In adults, neither ECCO (231) nor Cochrane review (234) recommend probiotics for induction of remission of mild-to-moderately active UC, despite some studies showing some effect of VSL\#3 $(227,244-247)$. There are no relevant data on probiotics in treatment of acute severe colitis (248).

Based on several RCTs and in accordance with systematic reviews $(235,249)$, ECCO recommend $E$ coli Nissle as an effective alternative to 5-ASA for maintenance therapy in adult UC (231).

Current pediatric UC guidelines (250) conclude in accordance with the Cochrane review (236) that there is insufficient evidence to recommend routine use of probiotics for induction or maintenance of remission in pediatric ambulatory UC patients. Some probiotics (VSL\#3, E coli Nissle) may, however, be considered in children with mild UC intolerant to 5-ASA, or as an adjuvant therapy in those with mild residual activity despite standard therapy. Therapy with VSL\#3 has also shown efficacy for maintaining antibiotic-induced remission and for preventing pouchitis in adults $(237,239,240)$. Recently, the probiotic mixture VSL\#3 has changed manufacturer and although it contains the same bacteria, its efficacy under the new manufacturing conditions has not yet been scientifically tested in IBD clinical trials.

\section{Crohn's Disease}

Only 1 relevant pediatric study was identified showing that Lactobacillus $G G$ is not superior to placebo in addition to standard maintenance therapy in pediatric CD (229). Moreover, a metaanalysis has even concluded that Lactobacillus $G G$ may increase incidence of relapse in children (251). Also, Saccharomyces boulardii has not shown any efficacy in preventing of relapse in CD adult patients in remission of disease (252). Current pediatric CD guidelines (45) as well as adult ECCO guidelines (232) and Cochrane review (238) are in accordance that there is no significant benefit of probiotics for reducing the risk of relapse compared to standard maintenance therapy.

What is the clinical efficacy and safety of prebiotics, when compared to no treatment, placebo, pharmacological treatment, or alternative nonpharmacological treatment in the induction and maintenance of remission of $\mathrm{UC}$ and $\mathrm{CD}$ ?

\section{Statement:}

- There is no evidence to the use of prebiotics and/or synbiotics in the induction and in the maintenance of remission of pediatric UC (adult: EL 2; pediatric: EL 5) and CD (adult: EL 2; pediatric: EL 5).

There are few data on the effect of prebiotics and synbiotics in pediatric IBD, with no published clinical trial. The majority of data in adults are limited by the small sample size, short duration and high dropout rate (253-260). A systematic review of RCT published in 2015, based on major limitations of the studies, including different agents used, sample size, and methodological issues, concluded that there is inconclusive evidence of a beneficial role of prebiotics and synbiotics in IBD (261).

What is the clinical efficacy and safety of dietary fibers, when compared to no treatment, placebo, pharmacological treatment, or alternative nonpharmacological treatment in the induction and maintenance of remission of $\mathrm{UC}$ and $\mathrm{CD}$ ?

\section{Statements:}

- Based on adult studies, fiber supplement intervention may be effective in the management of UC and pouchitis (adult: EL 2; pediatric: EL 5).

- There is no evidence to support high-fiber or lowfiber diet in CD (adult: EL 2; pediatric: EL 5).

\section{Practice points:}

- A possible effect of fiber supplementation associated with standard therapy has been reported in maintenance of remission (psyllium fiber), in active UC (germinated barley fiber), and in maintenance of remission in pouchitis (inulin-enriched oral supplement).

- Fiber restriction should not be recommended in patients with IBD without evidence of stricturing phenotype.

The scientific rationale of using dietary fiber in IBD relates to the production of metabolites (ie, SCFAs, particularly butyrate) and a beneficial influence on GI functions (262). Although no specific pediatric study has been performed, several trials in adults have evaluated the effectiveness and mechanisms of action of fiber in IBD. Based on the published RCT in adults and on 3 systematic reviews, there is limited evidence for the effectiveness of fiber supplementation in active $\mathrm{UC}$ and in maintenance of remission in $\mathrm{UC}$ and pouchitis $(253,254,263-274)$. Data in active UC are conflicting, 
TABLE 2. Exclusion diets and related risks in inflammatory bowel disease

\begin{tabular}{|c|c|c|}
\hline Exclusion diets & Not allowed foods & Risk $^{*}$ \\
\hline Ovo-lacto-vegetarian & Meat, fish & None \\
\hline Lactose free (reduced) & Animal milk/products high in lactose & None, if dairy products low in lactose are not avoided \\
\hline Vegan & All foods from animals & Low vitamin A, B12, D, Zinc, low protein intake \\
\hline Paleolithic diet & $\begin{array}{l}\text { Potatoes, legumes, cereal grain, domesticated meat, all dairy products, } \\
\text { juices, soft drinks, refined sugar }\end{array}$ & Increased fats intake; hypocalcemia \\
\hline Spec. carbohydrate diet & $\begin{array}{l}\text { Mono-, disaccharides, potatoes, Yams, legumes, canned products, } \\
\text { cereal grains, milks, sweets, margarine, beer }\end{array}$ & $\begin{array}{l}\text { Reduced caloric intake, B and D Hypovitaminosis, } \\
\text { hypocalcemia and hyposideremia }\end{array}$ \\
\hline Low FODMAP diet & $\begin{array}{l}\text { Mono-, di- oligosaccharides, fiber, wheat, rye, many fruits and } \\
\text { vegetables, milk }\end{array}$ & $\begin{array}{l}\text { If long-term, reduction of calcium, folate, thiamin, } \\
\text { vitamin B6 }\end{array}$ \\
\hline $\begin{array}{l}\mathrm{CD} \text { exclusion diet } \\
\quad(50 \% \text { polymeric formula })\end{array}$ & $\begin{array}{l}\text { Dairy products except the allowed formula, margarine, gluten, } \\
\text { processed and smoked meat and fish, canned products, yeast, soy, } \\
\text { potato or corn flours, soft drinks, fruit juices, alcoholic beverages, } \\
\text { coffee, chocolates, cakes, cookies, gums }\end{array}$ & None \\
\hline IgG4-based exclusion & Individual, mostly dairy, egg, pork, beef & Depending on the excluded foods \\
\hline
\end{tabular}

${ }^{*}$ Possible nutritional risks in children undergoing diets without nutritional advise. $\mathrm{CD}=\mathrm{Crohn}$ disease

with few studies reporting a possible effectiveness of fiber supplementation and others no effect on disease outcomes $(8,10,14)$

Dietary intervention studies did not show any significant benefit of high versus low-fiber diets in CD (263,264,269-271). Based on the current evidences, no dietary fiber restriction should be recommended to patients with IBD without evidence of stricturing phenotype, although monitoring of potential fiber intolerance intake should be performed (262).

\section{SPECIFIC DIETARY RESTRICTIONS FOR PEDIATRIC INFLAMMATORY BOWEL DISEASE}

\section{Statement:}

- Elimination or restrictive diet in children/adolescents with IBD should not be recommended unless potential benefits outweigh potential risks of the diet (EL 4).

Several diets restricting 1 or more foods from the diet have been advocated for pediatric and adult patients with IBD to improve symptoms and/or inflammation $(273,275-278)$. In general, restrictive diets may influence nutritional status, psychological and QoL. Nutritional restriction may result in unbalanced food intake with deficiency of certain macro- and micronutrients, which may have negative short- and long-term effect, particularly on the growing and developing child. Although adults can decide on a specific diet for themselves children depend on the decision and support by their caregivers. Diets should only be considered if they have proven benefit in reducing inflammation, symptoms or both. A list of reported diets is provided in Table 2 .

\section{Specific Carbohydrate Diet}

\section{Statement:}

- A specific carbohydrate diet (SCD) for induction or maintenance of remission in pediatric IBD patients should not be recommended (EL 4).

\section{Practice points:}

- SCD is an unbalanced diet due restriction of most carbohydrates leading to high-protein and high-fat intake, which has been associated with risk of $C D$ and UC.

- More evidence on the benefit of SCD from RCTs is needed before such a dietary restriction can be recommended to pediatric IBD patients.

The SCD restricts all carbohydrates (starch, polysaccharides, and disaccharides) except monosaccharides (glucose, fructose, and galactose). The hypothesis behind is that di- and polysaccharides are poorly absorbed resulting in overgrowth of bacteria and yeast with increased mucus production, small bowel injury and malabsorption. Two retrospective chart reviews of 7 and 26 children with IBD on a SCD showed improvement of symptoms and anthropometry $(279,280)$. Nine children with CD were prospectively enrolled in a trial of SCD while continuing their normal medication. Laboratory values, PCDAI, and videoendoscopy scores improved; however, there was no control group and total energy given was higher compared to the normal diet before starting SCD (281). Before there is more evidence in favor of an SCD, it cannot be recommended in children with IBD.

\section{Lactose-free Diet}

\section{Statements:}

- Symptoms of lactose malabsorption (abdominal pain, bloating, and diarrhea) overlap with symptoms of active IBD (EL 4).

- A diet with reduced lactose intake with monitoring of symptom improvement may be initiated in children/adolescents with IBD and symptoms suggestive of lactose malabsorption (EL 3).

\section{Practice point:}

- IBD patients should be counseled not to avoid dairy product, but to reduce high-lactose containing products and/or to use lactase treated products 
or enzyme replacement if lactase deficiency is suspected or intolerance is observed by the patient. If dietary calcium intake is low, calcium supplementation should be considered (282).

Hypersensitivity to lactose (lactose intolerance) results from primary or secondary deficient hydrolysis of lactose in the small intestine by the brush border enzyme lactase phlorizin hydrolase. The population proportion of people who are homozygous for the primary or adult onset of lactase deficiency varies from $<10 \%$ in white Northern Europeans to $>80$ to $90 \%$ in regions of Asia and Africa. Several studies in different populations showed that the primary genetic form of lactose intolerance occurs in the similar frequencies as in the respective control population with the same ethnic background (healthy controls and non-IBD relatives). Secondary lactose intolerance with lactase deficiency is due to multiple causes resulting in damage of the microvilli of the intestinal mucosa (eg, inflammation, ulceration, bacterial overgrowth) or reduction of the intestinal surface (resection). A few recent studies in children $(283,284)$ have shown that IBD patients, particularly with small bowel $\mathrm{CD}$, are more frequently lactose intolerant compared to healthy controls, when assessed by breath testing, symptoms and measurement of brush border enzyme activity. Risk of vitamin D deficiency and low Ca intake with negative impact on bone health has to be taken into account.

\section{Diet Low in Fermentable Oligo-, Di- and Monosaccharides and Polyol (FODMAPs)}

\section{Statement:}

- A low FODMAPs diet should not be recommended for induction to remission in children/adolescent with IBD (EL 5).

\section{Practice points:}

- A strict low FODMAP diet is highly restrictive.

- It may improve IBS symptoms for patients without evidence of inflammation. It may, however, decrease diversity and induce dysbiosis.

- FODMAP diet may be responsible for nutrient deficiencies ( $\mathrm{Ca}$, Folate, Thiamin, vitamin B6) and cannot be maintained for a long period. Dietary counseling is strongly advised.

Mono, di-, and polysaccharides and polyols are poorly absorbed resulting in increased intestinal permeability and increased functional symptoms (abdominal pain, diarrhea, and bloating) in patients with IBD (285). A few open nonblinded pilot studies improved functional GI symptoms in adult IBD patients $(286,287)$. No pediatric data are available. The diet is low in fiber serving as prebiotics, with potential negative effects on the microbiome and metabolome (288) and a risk of nutrient deficiencies.

\section{Crohn's Disease Exclusion Diet}

\section{Statement:}

- A Crohn's Disease Exclusion Diet (CDED) cannot be recommended as induction therapy due to insufficient evidence (EL 4).

\section{Practice point:}

- More evidence on the benefit and safety of CDED from RCTs is needed before such a dietary treatment can be recommended to pediatric IBD patients.

The diet is based on exclusion of multiple dietary components (289) and was evaluated for induction of remission in 34 children and 13 adults with mild-to-moderate $\mathrm{CD}$. The investigators used the diet in conjunction with $50 \%$ of caloric intake from 1 of 2 polymeric formulas. Remission by week 6 was achieved in $70 \%$ of patient, with significant drop in C-reactive protein (CRP) and erythrocyte sedimentation rate at both week 6 and week 12, with normalization of CRP in $70 \%$ of those entering remission (221). Fifteen patients in remission at week 6 , continued dietary restriction and performed a follow-up evaluation for mucosal healing, 11 of 15 achieved complete mucosal healing. This diet is currently being evaluated in a multinational multicenter randomized controlled trial.

\section{Other Restrictive Diets}

Several other diets have been suggested for treatment of active $\mathrm{CD}$ or UC including the paleolithic diet, a vegan diet, a gluten-free diet, a diet based on IgG4 testing against foods with excluding foods with high titers (277). In the latter diet the most common foods excluded were milk, beef, pork, and egg. The authors reported an improvement in the symptom score compared to a control group on a sham elimination diet; however, there was no significant improvement in fecal calprotectin or CRP (290). None of these diets should be recommended to children and adolescents with IBD at present.

\section{DIETARY COMPOUNDS AND THE RISK OF INFLAMMATORY BOWEL DISEASE}

\section{Definition}

Dietary compounds with proven effect on the intestinal barrier function directly or indirectly via the modification of the intestinal microbiota potentially implicated in triggering inflammatory or immune-mediated responses leading to IBD.

\section{Practice points:}

- Avoidance of "westernized" food (high-fat, highprotein, high-sugar, low in fruit and vegetables) identified in epidemiological studies as risk factor for the development of IBD may be considered.

- Avoidance of high-fat diet (including saturated milk fats) in patients with IBD may be considered.

- Avoidance of food or beverages containing large amounts of emulsifiers (ie, sauces, fast foods, margarines, ice-creams) may be considered.

The complex interaction of diet with the host's immune system (directly or indirectly via intestinal microbiota) is a key part in the development of chronic inflammation, the hallmark of IBD. When considering IBD and diet, there are 2 different aspects: to identify pre-illness dietary patterns/habits that confer a risk to develop IBD in susceptible individuals and to identify alimentary factors that impact on the inflammatory state of patients. Epidemiological or cohort data indicating specific dietary elements as risk 
factors for developing IBD are, however, often used as indirect evidence to recommend specific nutritional interventions to treat IBD.

Several epidemiological studies discuss a positive correlation between western life style (western diet with high amounts of unsaturated fatty acids, of proteins, a high sugar loads and low vegetables and fruits intake) and the risk of developing IBD $(291,292)$. A pediatric study confirmed recently a profound imbalance in fat, vegetables, and fruits consumption and the development of CD favoring this hypothesis (293). This is in line with adult data from Japan $(294,295)$ or UK $(296)$ indicating that an increased consumption of transunsaturated fatty acids increases the risk of developing UC. A prospective cohort study from France, however, failed to show any effect of fat or sugar intake, but the same study identified high protein intake (animal and fish proteins) as positively correlated to the risk of developing IBD (both CD or UC) (297), in keeping with the results of Shoda et al (294) who previously identified a weak positive correlation between high animal and fish protein intake and the risk to develop IBD. Increased dietary fiber intake has been associated with a lower risk of developing CD, but not UC (298). Recently, the results from EPIC study confirmed that high consumption of sugar and soft drinks and low consumption of vegetables are associated with adult UC risk (299).

Important experimental data support the hypothesis that food additives, such as emulsifiers or food thickeners (carboxymethyl cellulose $[\mathrm{CMC}]$, carrageenan, polysorbate $(\mathrm{P})-60$ or P-80, xanthan gum) can have detrimental effects on intestinal homeostasis. In vitro and in vivo analyses with CMC or P60 or P80 revealed that these emulsifiers alter the mucosal epithelial barrier directly or via a change of the intestinal microbiota biodiversity. They can modify the mucosa-adherent biofilm and the conditions for adhesion and translocation of mucosal bacteria. Chassaing et al (300) recently confirmed in an experimental model that 2 commonly used emulsifiers CMC and P80 create low-grade inflammation in wild-type and in genetically susceptible animals severe colitis, completing previous experimental work $(301,302)$. It is important to note that western diet (fast food and sweet beverages) is rich in emulsifiers. Roberts et al (303) highlighted recently that they observed a clear correlation between annual emulsifier consumption (in food and beverages) and the incidence of IBD, in line with previous studies (292). In the same line, high margarine (rich in emulsifying agents and hydrogenated fats) was identified by independent studies as being positively correlated with the development of $\mathrm{UC}$ and in some studies with CD $(304,305)$.

\section{REFERENCES}

1. Hartman C, Eliakim R, Shamir R. Nutritional status and nutritional therapy in inflammatory bowel diseases. World $J$ Gastroenterol 2009; 15:2570-8.

2. Lee D, Albenberg L, Compher C, et al. Diet in the pathogenesis and treatment of inflammatory bowel diseases. Gastroenterology 2015; 148:1087-106.

3. Shamir R, Phillip M, Levine A. Growth retardation in pediatric Crohn's disease: pathogenesis and interventions. Inflamm Bowel Dis 2007;13:620-8

4. Hwang C, Ross V, Mahadevan U. Micronutrient deficiencies in inflammatory bowel disease: from A to zinc. Inflamm Bowel Dis 2012;18:1961-81.

5. Shah ND, Parian AM, Mullin GE, et al. Oral diets and nutrition support for inflammatory bowel disease: what is the evidence? Nutr Clin Pract 2015;30:462-73.

6. Sousa Guerreiro C, Cravo M, Costa AR, et al. A comprehensive approach to evaluate nutritional status in Crohn's patients in the era of biologic therapy: a case-control study. Am J Gastroenterol 2007;102:2551-6.

7. Hartman C, Marderfeld L, Davidson K, et al. Food intake adequacy in children and adolescents with inflammatory bowel disease. J Pediatr Gastroenterol Nutr 2016;63:437-44.
8. Pons R, Whitten KE, Woodhead H, et al. Dietary intakes of children with Crohn's disease. Br J Nutr 2009;102:1052-7.

9. Johnson RK, Yon BA, Hankin JH. Dietary assessment and validation. In: Monsen ER, Van Horn L, eds. Research: Successful Approaches. New York: Elsevier; 2008:187-204.

10. Thompson FE, Subar AF. Dietary assessment methodology. In: Coulston A, Boushey C, eds. Nutrition in the Prevention and Treatment of Disease. San Diego: Academlic Press; 2008:3-39.

11. Shatenstein B, Amre D, Jabbour M, et al. Examining the relative validity of an adult food frequency questionnaire in children and adolescents. J Pediatr Gastroenterol Nutr 2010;51:645-52.

12. Rockett HR, Breitenbach M, Frazier AL, et al. Validation of a youth/ adolescent food frequency questionnaire. Prev Med 1997;26:808-16.

13. Turck D, Braegger CP, Colombo C, et al. ESPEN-ESPGHAN-ECFS guidelines on nutrition care for infants, children, and adults with cystic fibrosis. Clin Nutr 2016;35:557-77.

14. Cezard JP, Touati G, Alberti C, et al. Growth in paediatric Crohn's disease. Horm Res 2002;58(suppl 1):11-5.

15. Kanof ME, Lake AM, Bayless TM. Decreased height velocity in children and adolescents before the diagnosis of Crohn's disease. Gastroenterology 1988;95:1523-7.

16. Sentongo TA, Semeao EJ, Piccoli DA, et al. Growth, body composition, and nutritional status in children and adolescents with Crohn's disease. J Pediatr Gastroenterol Nutr 2000;31:33-40.

17. Markowitz J, Grancher K, Rosa J, et al. Growth failure in pediatric inflammatory bowel disease. J Pediatr Gastroenterol Nutr 1993;16: 373-80.

18. Motil KJ, Grand RJ, Davis-Kraft L, et al. Growth failure in children with inflammatory bowel disease: a prospective study. Gastroenterology 1993;105:681-91.

19. Griffiths AM, Nguyen P, Smith C, et al. Growth and clinical course of children with Crohn's disease. Gut 1993;34:939-43.

20. Vasseur F, Gower-Rousseau C, Vernier-Massouille G, et al. Nutritional status and growth in pediatric Crohn's disease: a population-based study. Am J Gastroenterol 2010;105:1893-900.

21. Pfefferkorn M, Burke G, Griffiths A, et al. Growth abnormalities persist in newly diagnosed children with Crohn disease despite current treatment paradigms. J Pediatr Gastroenterol Nutr 2009;48:168-74.

22. Sawczenko A, Ballinger AB, Savage MO, et al. Clinical features affecting final adult height in patients with pediatric-onset Crohn's disease. Pediatrics 2006;118:124-9.

23. Herzog D, Fournier N, Buehr P, et al. Early-onset Crohn's disease is a risk factor for smaller final height. Eur J Gastroenterol Hepatol 2014;26:1234-9.

24. Lee JJ, Escher JC, Shuman MJ, et al. Final adult height of children with inflammatory bowel disease is predicted by parental height and patient minimum height Z-score. Inflamm Bowel Dis 2010;16:1669-77.

25. Buderus S, Scholz D, Behrens R, et al., CEDATA-GPGE Study Group. Inflammatory bowel disease in pediatric patients: characteristics of newly diagnosed patients from the CEDATA-GPGE Registry. Dtsch Arztebl Int 2015;112:121-7.

26. Malik S, Mason A, Bakhshi A, et al. Growth in children receiving contemporary disease specific therapy for Crohn's disease. Arch Dis Child 2012;97:698-703.

27. Walters TD, Griffiths AM. Mechanisms of growth impairment in pediatric Crohn's disease. Nat Rev Gastroenterol Hepatol 2009;6:513-23.

28. Wine E, Reif SS, Leshinsky-Silver E, et al. Pediatric Crohn's disease and growth retardation: the role of genotype, phenotype, and disease severity. Pediatrics 2004;114:1281-6.

29. Lee JJ, Essers JB, Kugathasan S, et al. Association of linear growth impairment in pediatric Crohn's disease and a known height locus: a pilot study. Ann Hum Genet 2010;74:489-97.

30. Sawczenko A, Azooz O, Paraszczuk J, et al. Intestinal inflammationinduced growth retardation acts through IL-6 in rats and depends on the -174 IL-6 G/C polymorphism in children. Proc Natl Acad Sci U S A 2005; 102:13260-5.

31. Levine A, Shamir R, Wine E, et al. TNF promoter polymorphisms and modulation of growth retardation and disease severity in pediatric Crohn's disease. Am J Gastroenterol 2005;100:1598-604.

32. Ezri J, Marques-Vidal P, Nydegger A. Impact of disease and treatments on growth and puberty of pediatric patients with inflammatory bowel disease. Digestion 2012;85:308-19. 
33. Hyams JS, Moore RE, Leichtner AM, et al. Longitudinal assessment of type I procollagen in children with inflammatory bowel disease subjected to surgery. J Pediatr Gastroenterol Nutr 1989;8:68-74.

34. Leonard MB. Glucocorticoid-induced osteoporosis in children: impact of the underlying disease. Pediatrics 2007;119(suppl 2):S166-74.

35. Walther F, Fusch C, Radke M, et al. Osteoporosis in pediatric patients suffering from chronic inflammatory bowel disease with and without steroid treatment. J Pediatr Gastroenterol Nutr 2006;43:42-51.

36. Long MD, Crandall WV, Leibowitz IH, et al. Prevalence and epidemiology of overweight and obesity in children with inflammatory bowel disease. Inflamm Bowel Dis 2011;17:2162-8.

37. Kugathasan S, Nebel J, Skelton JA, et al. Body mass index in children with newly diagnosed inflammatory bowel disease: observations from two multicenter North American inception cohorts. J Pediatr 2007; 151:523-7.

38. Poon SS, Asher R, Jackson R, et al. Body mass index and smoking affect thioguanine nucleotide levels in inflammatory bowel disease. J Crohns Colitis 2015;9:640-6.

39. Thangarajah D, Hyde MJ, Konteti VK, et al. Systematic review: body composition in children with inflammatory bowel disease. Aliment Pharmacol Ther 2015;42:142-57.

40. Thayu M, Denson LA, Shults J, et al. Determinants of changes in linear growth and body composition in incident pediatric Crohn's disease. Gastroenterology 2010;139:430-8.

41. Ballinger AB, Savage MO, Sanderson IR. Delayed puberty associated with inflammatory bowel disease. Pediatr Res 2003;53:205-10.

42. DeBoer MD, Denson LA. Delays in puberty, growth, and accrual of bone mineral density in pediatric Crohn's disease: despite temporal changes in disease severity, the need for monitoring remains. J Pediatr 2013;163:17-22.

43. Mason A, Malik S, McMillan M, et al. A prospective longitudinal study of growth and pubertal progress in adolescents with inflammatory bowel disease. Horm Res Paediatr 2015;83:45-54.

44. Hill RJ. Update on nutritional status, body composition and growth in paediatric inflammatory bowel disease. World $J$ Gastroenterol 2014;20:3191-7.

45. Ruemmele FM, Veres G, Kolho KL, et al., European Crohn's and Colitis Organisation; European Society of Pediatric Gastroenterology, Hepatology and Nutrition. Consensus guidelines of ECCO/ESPGHAN on the medical management of pediatric Crohn's disease. J Crohns Colitis 2014;8:1179-207.

46. Barot LR, Rombeau JL, Feurer ID, et al. Caloric requirements in patients with inflammatory bowel disease. Ann Surg 1982;195:214-8.

47. Sasaki M, Johtatsu T, Kurihara M, et al. Energy metabolism in Japanese patients with Crohn's disease. J Clin Biochem Nutr 2010;46:68-72.

48. Kushner RF, Schoeller DA. Resting and total energy expenditure in patients with inflammatory bowel disease. Am J Clin Nutr 1991;53:161-5.

49. Varille V, Cézard JP, de Lagausie P, et al. Resting energy expenditure before and after surgical resection of gut lesions in pediatric Crohn's disease. J Pediatr Gastroenterol Nutr 1996;23:13-9.

50. Zoli G, Katelaris PH, Garrow J, et al. Increased energy expenditure in growing adolescents with Crohn's disease. Dig Dis Sci 1996;41:1754-9.

51. Al-Jaouni R, Hebuterne X, Pouget I, et al. Energy metabolism and substrate oxidation in patients with Crohn's disease. Nutrition 2000; $16: 173-8$.

52. Schneeweiss B, Lochs H, Zauner C, et al. Energy and substrate metabolism in patients with active Crohn's disease. J Nutr 1999;129:844-8.

53. Azcue M, Rashid M, Griffiths A, et al. Energy expenditure and body composition in children with Crohn's disease: effect of enteral nutrition and treatment with prednisolone. Gut 1997;41:203-8.

54. Wiskin AE, Wootton SA, Culliford DJ, et al. Impact of disease activity on resting energy expenditure in children with inflammatory bowel disease. Clin Nutr 2009;28:652-6.

55. Steiner SJ, Pfefferkorn MD, Fitzgerald JF, et al. Protein and energy metabolism response to the initial dose of infliximab in children with Crohn's disease. Inflamm Bowel Dis 2007;13:737-44.

56. Hill RJ, Lewindon PJ, Withers GD, et al. Ability of commonly used prediction equations to predict resting energy expenditure in children with inflammatory bowel disease. Inflamm Bowel Dis 2011;17: 1587-93.
57. Cormier K, Mager D, Bannister L, et al. Resting energy expenditure in the parenterally fed pediatric population with Crohn's disease. JPEN J Parenter Enteral Nutr 2005;29:102-7.

58. Hart JW, Bremner AR, Wootton SA, et al. Measured versus predicted energy expenditure in children with inactive Crohn's disease. Clin Nutr 2005;24:1047-55.

59. Wiskin AE, Wootton SA, Cornelius VR, et al. No relation between disease activity measured by multiple methods and REE in childhood Crohn disease. J Pediatr Gastroenterol Nutr 2012;54:271-6.

60. Steiner SJ, Pfefferkorn MD, Fitzgerald JF, et al. Carbohydrate and lipid metabolism following infliximab therapy in pediatric Crohn's disease. Pediatr Res 2008;64:673-6.

61. Diamanti A, Basso MS, Gambarara M, et al. Positive impact of blocking tumor necrosis factor alpha on the nutritional status in pediatric Crohn's disease patients. Int J Colorectal Dis 2009;24:19-25.

62. Thomas AG, Miller V, Taylor F, et al. Whole body protein turnover in childhood Crohn's disease. Gut 1992;33:675-7.

63. Steiner SJ, Noe JD, Denne SC. Corticosteroids increase protein breakdown and loss in newly diagnosed pediatric Crohn disease. Pediatr Res 2011;70:484-8.

64. Motil KJ, Grand RJ, Maletskos CJ, et al. The effect of disease, drug, and diet on whole body protein metabolism in adolescents with Crohn disease and growth failure. J Pediatr 1982;101:345-51.

65. Martinez-Medina M, Denizot J, Dreux N, et al. Western diet induces dysbiosis with increased $E$ coli in CEABAC10 mice, alters host barrier function favouring AIEC colonisation. Gut 2014;63: 116-24.

66. Suzuki T, Hara H. Dietary fat and bile juice, but not obesity, are responsible for the increase in small intestinal permeability induced through the suppression of tight junction protein expression in LETO and OLETF rats. Nutr Metab 2010;7:19.

67. Lev-Tzion R, Griffiths AM, Leder O, et al. Omega 3 fatty acids (fish oil) for maintenance of remission in Crohn's disease. Cochrane Database Syst Rev (2):2014:CD006320.

68. Turner D, Steinhart AH, Griffiths AM. Omega 3 fatty acids (fish oil) for maintenance of remission in ulcerative colitis. Cochrane Database Syst Rev (3):2007:CD006443.

69. Saltik-Temizel IN, Eren M, Demir H, et al. Bone mineralization in children with inflammatory bowel disease: what is the role of zinc? Turk J Gastroenterol 2008;19:234-8.

70. Alkhouri RH, Hashmi H, Baker RD, et al. Vitamin and mineral status in patients with inflammatory bowel disease. J Pediatr Gastroenterol Nutr 2013;56:89-92.

71. Santucci NR, Alkhouri RH, Baker RD, et al. Vitamin and zinc status pretreatment and posttreatment in patients with inflammatory bowel disease. J Pediatr Gastroenterol Nutr 2014;59:455-7.

72. Sikora SK, Spady D, Prosser C, et al. Trace elements and vitamins at diagnosis in pediatric-onset inflammatory bowel disease. Clin Pediatr 2011;50:488-92.

73. Vagianos K, Bector S, McConnell J, et al. Nutrition assessment of patients with inflammatory bowel disease. JPEN J Parenter Enteral Nutr 2007;31:311-9.

74. Lansdown AB, Mirastschijski U, Stubbs N, et al. Zinc in wound healing: theoretical, experimental, and clinical aspects. Wound Repair Regen 2007; 15:2-16.

75. Geerling BJ, Badart-Smook A, Stockbrugger RW, et al. Comprehensive nutritional status in recently diagnosed patients with inflammatory bowel disease compared with population controls. Eur J Clin Nutr 2000;54:514-21.

76. Sturniolo GC, Mestriner C, Lecis PE, et al. Altered plasma and mucosal concentrations of trace elements and antioxidants in active ulcerative colitis. Scand J Gastroenterol 1998;33:644-9.

77. Ringstad J, Kildebo S, Thomassen Y. Serum selenium, copper, and zinc concentrations in Crohn's disease and ulcerative colitis. Scand J Gastroenterol 1993;28:605-8.

78. Fernández-Banares F, Mingorance MD, Esteve M, et al. Serum zinc, copper, and selenium levels in inflammatory bowel disease: effect of total enteral nutrition on trace element status. Am J Gastroenterol 1990;85:1584-9.

79. Gentschew L, Bishop KS, Han DY, et al. Selenium, selenoprotein genes and Crohn's disease in a case-control population from Auckland, New Zealand. Nutrients 2012;4:1247-59. 
80. Ojuawo A, Keith L. The serum concentrations of zinc, copper and selenium in children with inflammatory bowel disease. Cent Afr J Med 2002;48:116-9.

81. Wiskin AE, Fleming BJ, Wootton SA, et al. Anaemia and iron deficiency in children with inflammatory bowel disease. J Crohns Colitis 2012;6:687-91.

82. Goodhand JR, Kamperidis N, Rao A, et al. Prevalence and management of anemia in children, adolescents, and adults with inflammatory bowel disease. Inflamm Bowel Dis 2012;18:513-9.

83. Dignass AU, Gasche C, Bettenworth D, et al., European Crohn's and Colitis Organisation [ECCO. European consensus on the diagnosis and management of iron deficiency and anaemia in inflammatory bowel diseases. J Crohns Colitis 2015;9:211-22.

84. Pels LP, Van de Vijver E, Waalkens HJ, et al. Slow hematological recovery in children with IBD-associated anemia in cases of "expectant management". J Pediatr Gastroenterol Nutr 2010;51:708-13.

85. Lugg S, Beal F, Nightingale $P$, et al. Iron treatment and inflammatory bowel disease: what happens in real practice? J Crohns Colitis 2014;8:876-80.

86. Bruner AB, Joffe A, Duggan AK, et al. Randomised study of cognitive effects of iron supplementation in non-anaemic iron-deficient adolescent girls. Lancet 1996;348:992-6.

87. Krayenbuehl PA, Battegay E, Breymann C, et al. Intravenous iron for the treatment of fatigue in nonanemic, premenopausal women with low serum ferritin concentration. Blood 2011;118:3222-7.

88. Semrin G, Fishman DS, Bousvaros A, et al. Impaired intestinal iron absorption in Crohn's disease correlates with disease activity and markers of inflammation. Inflamm Bowel Dis 2006;12:1101-6.

89. Bregman DB, Morris D, Koch TA, et al. Hepcidin levels predict nonresponsiveness to oral iron therapy in patients with iron deficiency anemia. Am J Hematol 2013;88:97-101.

90. Weiss G, Goodnough LT. Anemia of chronic disease. $N$ Engl J Med 2005;352:1011-23.

91. Sankaran VG, Weiss MJ. Anemia: progress in molecular mechanisms and therapies. Nat Med 2015;21:221-30.

92. Martinelli M, Strisciuglio C, Alessandrella A, et al. Serum hepcidin and iron absorption in paediatric inflammatory bowel disease. J Crohns Colitis 2016;10:566-74.

93. Mantadakis E. Advances in pediatric intravenous iron therapy. Pediatr Blood Cancer 2016;63:11-6.

94. Lee TW, Kolber MR, Fedorak RN, et al. Iron replacement therapy in inflammatory bowel disease patients with iron deficiency anemia: A systematic review and meta-analysis. J Crohns Colitis 2012;6:267-75.

95. Schroder O, Mickisch O, Seidler U, et al. Intravenous iron sucrose versus oral iron supplementation for the treatment of iron deficiency anemia in patients with inflammatory bowel disease-a randomized, controlled, open-label, multicenter study. Am J Gastroenterol 2005;100:2503-9.

96. Jaeggi T, Kortman GAM, Moretti D, et al. Iron fortification adversely affects the gut microbiome, increases pathogen abundance and induces intestinal inflammation in Kenyan infants. Gut 2015;64:731-42.

97. Lee T, Clavel T, Smirnov K, et al. Oral versus intravenous iron replacement therapy distinctly alters the gut microbiota and metabolome in patients with IBD. Gut 2016;66:863-71.

98. Weiss G. Dietary iron supplementation: a proinflammatory attack on the intestine? Gut 2015;64:696-7.

99. Rampton DS, Goodhand JR, Joshi NM, et al. Oral iron treatment response and predictors in anaemic adolescents and adults with IBD: a prospective controlled open-label trial. J Crohns Colitis 2017;11:706-15.

100. Halpin TC Jr, Bertino JS, Rothstein FC, et al. Iron-deficiency anemia in childhood inflammatory bowel disease: treatment with intravenous iron-dextran. JPEN J Parenter Enteral Nutr 1982;6:9-11.

101. Mamula P, Piccoli DA, Peck SN, et al. Total dose intravenous infusion of iron dextran for iron-deficiency anemia in children with inflammatory bowel disease. J Pediatr Gastroenterol Nutr 2002;34:286-90.

102. Laass MW, Straub S, Chainey S, et al. Effectiveness and safety of ferric carboxymaltose treatment in children and adolescents with inflammatory bowel disease and other gastrointestinal diseases. BMC Gastroenterol 2014;14:184

103. Kulnigg S, Stoinov S, Simanenkov V, et al. A novel intravenous iron formulation for treatment of anemia in inflammatory bowel disease: the ferric carboxymaltose (FERINJECT) randomized controlled trial. Am J Gastroenterol 2008;103:1182-92.
104. Evstatiev R, Alexeeva O, Bokemeyer B, et al. Ferric carboxymaltose prevents recurrence of anemia in patients with inflammatory bowel disease. Clin Gastroenterol Hepatol 2013;11:269-77.

105. Evstatiev R, Marteau P, Iqbal T, et al., FERGI Study Group. FERGIcor, a randomized controlled trial on ferric carboxymaltose for iron deficiency anemia in inflammatory bowel disease. Gastroenterology 2011;141:846-53e1-2.

106. Beigel F, Lohr B, Laubender RP, et al. Iron status and analysis of efficacy and safety of ferric carboxymaltose treatment in patients with inflammatory bowel disease. Digestion 2012;85:47-54.

107. Plantz K, Maxwell E, Mamula P, et al. O-022 intravenous iron sucrose for treatment of iron deficiency anemia in pediatric inflammatory bowel disease. Inflamm Bowel Dis 2016;22(suppl 1):S8.

108. Lindgren $\mathrm{S}$, Wikman $\mathrm{O}$, Befrits $\mathrm{R}$, et al. Intravenous iron sucrose is superior to oral iron sulphate for correcting anaemia and restoring iron stores in IBD patients: a randomized, controlled, evaluator-blind, multicentre study. Scand J Gastroenterol 2009;44:838-45.

109. Hessov I. Magnesium deficiency in Crohn's disease. Clin Nutr 1990;9:297-8.

110. Galland L. Magnesium and inflammatory bowel disease. Magnesium 1988:7:78-83.

111. Filippi J, Al-Jaouni R, Wiroth JB, et al. Nutritional deficiencies in patients with Crohn's disease in remission. Inflamm Bowel Dis 2006;12:185-91.

112. Bernstein CN, Seeger LL, Anton PA, et al. A randomized, placebocontrolled trial of calcium supplementation for decreased bone density in corticosteroid-using patients with inflammatory bowel disease: a pilot study. Aliment Pharmacol Ther 1996;10:777-86.

113. Benchimol EI, Ward LM, Gallagher JC, et al. Effect of calcium and vitamin D supplementation on bone mineral density in children with inflammatory bowel disease. J Pediatr Gastroenterol Nutr 2007; 45:538-45.

114. Schmidt S, Mellstrom D, Norjavaara E, et al. Low bone mineral density in children and adolescents with inflammatory bowel disease: a population-based study from Western Sweden. Inflamm Bowel Dis 2009; $15: 1844-50$.

115. Schmidt S, Mellstrom D, Norjavaara E, et al. Longitudinal assessment of bone mineral density in children and adolescents with inflammatory bowel disease. J Pediatr Gastroenterol Nutr 2012;55:511-8.

116. Sylvester FA, Wyzga N, Hyams JS, et al. Natural history of bone metabolism and bone mineral density in children with inflammatory bowel disease. Inflamm Bowel Dis 2007;13:42-50.

117. Laakso S, Valta H, Verkasalo M, et al. Impaired bone health in inflammatory bowel disease: a case-control study in 80 pediatric patients. Calcif Tissue Int 2012;91:121-30.

118. Gokhale R, Favus MJ, Karrison T, et al. Bone mineral density assessment in children with inflammatory bowel disease. Gastroenterology 1998;114:902-11.

119. Paganelli M, Albanese C, Borrelli O, et al. Inflammation is the main determinant of low bone mineral density in pediatric inflammatory bowel disease. Inflamm Bowel Dis 2007;13:416-23.

120. Lopes LH, Sdepanian VL, Szejnfeld VL, et al. Risk factors for low bone mineral density in children and adolescents with inflammatory bowel disease. Dig Dis Sci 2008;53:2746-53.

121. Kanis JA. Assessment of fracture risk and its application to screening for postmenopausal osteoporosis: synopsis of a WHO report. WHO Study Group. Osteoporos Int 1994;4:368-81.

122. Cosman F, de Beur SJ, LeBoff MS, et al. Clinician's guide to prevention and treatment of osteoporosis. Osteoporos Int 2014;25: 2359-81.

123. Braegger C, Campoy C, Colomb V, et al. Vitamin D in the healthy European paediatric population. J Pediatr Gastroenterol Nutr 2013;56: 692-701.

124. Wagner CL, Greer FR. American Academy of Pediatrics Section on Breastfeeding; American Academy of Pediatrics Committee on Nutrition. Prevention of rickets and vitamin D deficiency in infants, children, and adolescents. Pediatrics 2008;122:1142-52.

125. Lindenbaum J. Drugs and vitamin B12 and folate metabolism. Curr Concepts Nutr 1983;12:73-87.

126. Sadeghian M, Saneei P, Siassi F, et al. Vitamin D status in relation to Crohn's disease: meta-analysis of observational studies. Nutrition 2016;32:505-14. 
127. Torki M, Gholamrezaei A, Mirbagher L, et al. Vitamin D deficiency associated with disease activity in patients with inflammatory bowel diseases. Dig Dis Sci 2015;60:3085-91.

128. Kabbani TA, Koutroubakis IE, Schoen RE, et al. Association of vitamin D level with clinical status in inflammatory bowel disease: a 5-year longitudinal study. Am J Gastroenterol 2016;111:712-9.

129. Castro FD, Magalhães J, Carvalho PB, et al. Lower levels of vitamin D correlate with clinical disease activity and quality of life in inflammatory bowel disease. Arq Gastroenterol 2015;52:260-5.

130. Veit LE, Maranda L, Fong J, et al. The vitamin D status in inflammatory bowel disease. PloS One 2014;9:e101583.

131. Pappa HM, Gordon CM, Saslowsky TM, et al. Vitamin D status in children and young adults with inflammatory bowel disease. Pediatrics 2006;118:1950-61.

132. El-Matary W, Sikora S, Spady D. Bone mineral density, vitamin D, and disease activity in children newly diagnosed with inflammatory bowel disease. Dig Dis Sci 2011;56:825-9.

133. Levin AD, Wadhera V, Leach ST, et al. Vitamin D deficiency in children with inflammatory bowel disease. Dig Dis Sci 2011;56: 830-6.

134. Wingate KE, Jacobson K, Issenman R, et al. 25-Hydroxyvitamin D concentrations in children with Crohn's disease supplemented with either 2000 or 400 IU daily for 6 months: a randomized controlled study. J Pediatr 2014;164:860-5.

135. Pappa HM, Mitchell PD, Jiang H, et al. Maintenance of optimal vitamin D status in children and adolescents with inflammatory bowel disease: a randomized clinical trial comparing two regimens. $J$ Clin Endocrinol Metab 2014;99:3408-17.

136. Pappa HM, Mitchell PD, Jiang H, et al. Treatment of vitamin D insufficiency in children and adolescents with inflammatory bowel disease: a randomized clinical trial comparing three regimens. $J$ Clin Endocrinol Metab 2012;97:2134-42.

137. Simek RZ, Prince J, Syed S, et al. Pilot study evaluating efficacy of 2 regimens for hypovitaminosis D repletion in pediatric inflammatory bowel disease. J Pediatr Gastroenterol Nutr 2016;62:252-8.

138. Shepherd D, Day AS, Leach ST, et al. Single high-dose oral vitamin D3 therapy (Stoss): a solution to vitamin D deficiency in Children with inflammatory bowel disease? J Pediatr Gastroenterol Nutr 2015;61: 411-4.

139. Siffledeen JS, Fedorak RN, Siminoski K, et al. Randomized trial of etidronate plus calcium and vitamin D for treatment of low bone mineral density in Crohn's disease. Clin Gastroenterol Hepatol 2005;3:122-32.

140. D'Odorico A, Bortolan S, Cardin R, et al. Reduced plasma antioxidant concentrations and increased oxidative DNA damage in inflammatory bowel disease. Scand J Gastroenterol 2001;36:1289-94.

141. Hengstermann S, Valentini L, Schaper L, et al. Altered status of antioxidant vitamins and fatty acids in patients with inactive inflammatory bowel disease. Clin Nutr 2008;27:571-8.

142. Hashemi J, Asadi J, Amiriani T, et al. Serum vitamins A and E deficiencies in patients with inflammatory bowel disease. Saudi Med J 2013;34:432-4.

143. Bousvaros A, Zurakowski D, Duggan C, et al. Vitamins A and E serum levels in children and young adults with inflammatory bowel disease: effect of disease activity. J Pediatr Gastroenterol Nutr 1998;26:129-35.

144. Debier C. Vitamin E during pre- and postnatal periods. Vitam Horm 2007;76:357-73

145. Kuroki F, Iida M, Tominaga M, et al. Multiple vitamin status in Crohn's disease. Correlation with disease activity. Dig Dis Sci 1993;38:1614-8.

146. Krasinski SD, Russell RM, Furie BC, et al. The prevalence of vitamin $\mathrm{K}$ deficiency in chronic gastrointestinal disorders. Am J Clin Nutr 1985;41:639-43.

147. Schoon EJ, Müller MC, Vermeer C, et al. Low serum and bone vitamin $\mathrm{K}$ status in patients with longstanding Crohn's disease: another pathogenetic factor of osteoporosis in Crohn's disease? Gut 2001;48:473-7.

148. Duggan P, O’Brien M, Kiely M, et al. Vitamin K status in patients with Crohn's disease and relationship to bone turnover. Am J Gastroenterol 2004;99:2178-85.

149. Nowak JK, Grzybowska-Chlebowczyk U, Landowski P, et al. Prevalence and correlates of vitamin $\mathrm{K}$ deficiency in children with inflammatory bowel disease. Sci Rep 2014;4:4768.
150. Fernandez-Baares F, Abad-Lacruz A, Xiol X, et al. Vitamin status in patients with inflammatory bowel disease. Am J Gastroenterol 1989;84:744-8.

151. Hodges $\mathrm{P}$, Gee M, Grace M, et al. Vitamin and iron intake in patients with Crohn's disease. J Am Diet Assoc 1984;84:52-8.

152. Urbano AP, Sassaki LY, Dorna MS, et al. Nutritional intake according to injury extent in ulcerative colitis patients. J Hum Nutr Diet 2013;26:445-51.

153. Tsiountsioura M, Wong JE, Upton J, et al. Detailed assessment of nutritional status and eating patterns in children with gastrointestinal diseases attending an outpatients clinic and contemporary healthy controls. Eur J Clin Nutr 2014;68:700-6.

154. Saibeni S, Cattaneo M, Vecchi M, et al. Low vitamin B(6) plasma levels, a risk factor for thrombosis, in inflammatory bowel disease: role of inflammation and correlation with acute phase reactants. Am J Gastroenterol 2003;98:112-7.

155. Yakut M, Ustun Y, Kabacam G, et al. Serum vitamin B12 and folate status in patients with inflammatory bowel diseases. Eur J Intern Med 2010;21:320-3.

156. Vagianos K, Bernstein CN, Homocysteinemia. B vitamin status among adult patients with inflammatory bowel disease: a one-year prospective follow-up study. Inflamm Bowel Dis 2012;18:718-24.

157. Bermejo F, Algaba A, Guerra I, et al. Should we monitor vitamin B12 and folate levels in Crohn's disease patients? Scand J Gastroenterol 2013;48:1272-7.

158. Nakano E, Taylor CJ, Chada L, et al. Hyperhomocystinemia in children with inflammatory bowel disease. J Pediatr Gastroenterol Nutr 2003;37:586-90.

159. Heyman MB, Garnett EA, Shaikh N, et al. Folate concentrations in pediatric patients with newly diagnosed inflammatory bowel disease. Am J Clin Nutr 2009;89:545-50.

160. Phelip JM, Ducros V, Faucheron JL, et al. Association of hyperhomocysteinemia and folate deficiency with colon tumors in patients with inflammatory bowel disease. Inflamm Bowel Dis 2008;14:242-8.

161. Shea B, Swinden MV, Tanjong Ghogomu E, et al. Folic acid and folinic acid for reducing side effects in patients receiving methotrexate for rheumatoid arthritis. Cochrane Database Syst Rev (5):2013: CD000951.

162. Saibeni S, Bollani S, Losco A, et al. The use of methotrexate for treatment of inflammatory bowel disease in clinical practice. Dig Liver Dis 2012;44:123-7.

163. McNulty H, Scott JM. Intake and status of folate and related Bvitamins: considerations and challenges in achieving optimal status. Br J Nutr 2008;99(suppl 3):S48-54.

164. Savage DG, Lindenbaum J, Stabler SP, et al. Sensitivity of serum methylmalonic acid and total homocysteine determinations for diagnosing cobalamin and folate deficiencies. Am J Med 1994;96:239-46.

165. Battat R, Kopylov U, Szilagyi A, et al. Vitamin B12 deficiency in inflammatory bowel disease: prevalence, risk factors, evaluation, and management. Inflamm Bowel Dis 2014;20:1120-8.

166. Headstrom PD, Rulyak SJ, Lee SD. Prevalence of and risk factors for vitamin B(12) deficiency in patients with Crohn's disease. Inflamm Bowel Dis 2008;14:217-23.

167. Ward MG, Kariyawasam VC, Mogan SB, et al. Prevalence and risk factors for functional vitamin B12 deficiency in patients with Crohn's disease. Inflamm Bowel Dis 2015;21:2839-47.

168. Coull DB, Tait RC, Anderson JH, et al. Vitamin B12 deficiency following restorative proctocolectomy. Colorectal Dis 2007;9:562-6.

169. Thompson WG, Wrathell E. The relation between ileal resection and vitamin B12 absorption. Can J Surg 1977;20:461-4.

170. Duerksen DR, Fallows G, Bernstein CN. Vitamin B12 malabsorption in patients with limited ileal resection. Nutrition 2006;22:1210-3.

171. Stabler SP. Vitamin B12 deficiency. N Engl J Med 2013;368:2041-2.

172. Elriz K, Palascak-Juif V, Joly F, et al. Crohn's disease patients with chronic intestinal failure receiving long-term parenteral nutrition: a cross-national adult study. Aliment Pharmacol Ther 2011;34:931-40.

173. Abi Nader E, Lambe C, Talbotec C, et al. Outcome of home parenteral nutrition in 251 children over a 14-y period: report of a single center. Am J Clin Nutr 2016;103:1327-36.

174. Greenberg GR, Fleming CR, Jeejeebhoy KN, et al. Controlled trial of bowel rest and nutritional support in the management of Crohn's disease. Gut 1988;29:1309-15. 
175. Jones VA. Comparison of total parenteral nutrition and elemental diet in induction of remission of Crohn's disease. Long-term maintenance of remission by personalized food exclusion diets. Dig Dis Sci 1987;32(12 suppl):100S-7S.

176. Zachos M, Tondeur M, Griffiths AM. Enteral nutritional therapy for induction of remission in Crohn's disease. Cochrane Database Syst $\operatorname{Rev}(1): 2007: \mathrm{CD} 000542$.

177. Heuschkel RB, Menache CC, Megerian JT, et al. Enteral nutrition and corticosteroids in the treatment of acute Crohn's disease in children. $J$ Pediatr Gastroenterol Nutr 2000;31:8-15.

178. Dziechciarz P, Horvath A, Shamir R, et al. Meta-analysis: enteral nutrition in active Crohn's disease in children. Aliment Pharmacol Ther 2007;26:795-806.

179. Grogan JL, Casson DH, Terry A, et al. Enteral feeding therapy for newly diagnosed pediatric Crohn's disease: a double-blind randomized controlled trial with two years follow-up. Inflamm Bowel Dis 2012;18:246-53.

180. Buchanan E, Gaunt WW, Cardigan T, et al. The use of exclusive enteral nutrition for induction of remission in children with Crohn's disease demonstrates that disease phenotype does not influence clinical remission. Aliment Pharmacol Ther 2009;30:501-7.

181. Rubio A, Pigneur B, Garnier-Lengliné H, et al. The efficacy of exclusive nutritional therapy in paediatric Crohn's disease, comparing fractionated oral vs. continuous enteral feeding. Aliment Pharmacol Ther 2011;33:1332-9.

182. Levine A, Turner D, Pfeffer Gik T, et al. Comparison of outcomes parameters for induction of remission in new onset pediatric Crohn's disease: evaluation of the porto IBD group "growth relapse and outcomes with therapy" (GROWTH CD) study. Inflamm Bowel Dis 2014;20:278-85.

183. Lee D, Baldassano RN, Otley AR, et al. Comparative effectiveness of nutritional and biological therapy in North American Children with active Crohn's disease. Inflamm Bowel Dis 2015;21:1786-93.

184. Day AS, Whitten KE, Lemberg DA, et al. Exclusive enteral feeding as primary therapy for Crohn's disease in Australian children and adolescents: a feasible and effective approach. J Gastroenterol Hepatol 2006;21:1609-14.

185. Knight C, El-Matary W, Spray C, et al. Long-term outcome of nutritional therapy in paediatric Crohn's disease. Clin Nutr 2005; 24:775-9.

186. Cameron FL, Gerasimidis K, Papangelou A, et al. Clinical progress in the two years following a course of exclusive enteral nutrition in 109 paediatric patients with Crohn's disease. Aliment Pharmacol Ther 2013;37:622-9.

187. Frivolt K, Schwerd T, Werkstetter KJ, et al. Repeated exclusive enteral nutrition in the treatment of paediatric Crohn's disease: predictors of efficacy and outcome. Aliment Pharmacol Ther 2014;39:1398-407.

188. Akobeng AK, Miller V, Stanton J, et al. Double-blind randomized controlled trial of glutamine-enriched polymeric diet in the treatment of active Crohn's disease. J Pediatr Gastroenterol Nutr 2000;30:7884.

189. Ludvigsson JF, Krantz M, Bodin L, et al. Elemental versus polymeric enteral nutrition in paediatric Crohn's disease: a multicentre randomized controlled trial. Acta Paediatr 2004;93:327-35.

190. Verma S, Brown S, Kirkwood B, et al. Polymeric versus elemental diet as primary treatment in active Crohn's disease: a randomized, doubleblind trial. Am J Gastroenterol 2000;95:735-9.

191. Akobeng AK, Thomas AG. Enteral nutrition for maintenance of remission in Crohn's disease. Cochrane Database Syst Rev 2007;(3):CD005984.

192. Rodrigues AF, Johnson T, Davies P, et al. Does polymeric formula improve adherence to liquid diet therapy in children with active Crohn's disease? Arch Dis Child 2007;92:767-70.

193. Sakurai T, Matsui T, Yao T, et al. Short-term efficacy of enteral nutrition in the treatment of active Crohn's disease: a randomized, controlled trial comparing nutrient formulas. JPEN J Parenter Enteral Nutr 2002;26:98-103.

194. Gassull MA, Fernandez-Banares F, Cabre E, et al., Eurpoean Group on Enteral Nutrition in Crohn's Disease. Fat composition may be a clue to explain the primary therapeutic effect of enteral nutrition in Crohn's disease: results of a double blind randomised multicentre European trial. Gut 2002;51:164-8.
195. Afzal NA, Van Der Zaag-Loonen HJ, Arnaud-Battandier F, et al. Improvement in quality of life of children with acute Crohn's disease does not parallel mucosal healing after treatment with exclusive enteral nutrition. Aliment Pharmacol Ther 2004;20:167-72.

196. Whitten KE, Rogers P, Ooi CY, et al. International survey of enteral nutrition protocols used in children with Crohn's disease. J Dig Dis 2012;13:107-12.

197. Fell JM, Paintin M, Arnaud-Battandier F, et al. Mucosal healing and a fall in mucosal pro-inflammatory cytokine mRNA induced by a specific oral polymeric diet in paediatric Crohn's disease. Aliment Pharmacol Ther 2000;14:281-9.

198. Faiman A, Mutalib M, Moylan A, et al. Standard versus rapid food reintroduction after exclusive enteral nutritional therapy in paediatric Crohn's disease. Eur J Gastroenterol Hepatol 2014;26:276-81.

199. Afzal NA, Davies S, Paintin M, et al. Colonic Crohn's disease in children does not respond well to treatment with enteral nutrition if the ileum is not involved. Dig Dis Sci 2005;50:1471-5.

200. Wong S, Lemberg DA, Day AS. Exclusive enteral nutrition in the management of perianal Crohn's disease in children. J Dig Dis 2010;11:185-8.

201. Day AS, Whitten KE, Sidler M, et al. Systematic review: nutritional therapy in paediatric Crohn's disease. Aliment Pharmacol Ther 2008;27:293-307.

202. Borrelli O, Cordischi L, Cirulli M, et al. Polymeric diet alone versus corticosteroids in the treatment of active pediatric Crohn's disease: a randomized controlled open-label trial. Clin Gastroenterol Hepatol 2006;4:744-53.

203. Mehanna HM, Moledina J, Travis J. Refeeding syndrome: what it is, and how to prevent and treat it. BMJ 2008;336:1495-8.

204. Afzal NA, Addai S, Fagbemi A, et al. Refeeding syndrome with enteral nutrition in children: a case report, literature review and clinical guidelines. Clin Nutr 2002;21:515-20.

205. Akobeng AK, Thomas AG. Refeeding syndrome following exclusive enteral nutritional treatment in Crohn disease. J Pediatr Gastroenterol Nutr 2010;51:364-6.

206. Beattie RM, Schiffrin EJ, Donnet-Hughes A, et al. Polymeric nutrition as the primary therapy in children with small bowel Crohn's disease. Aliment Pharmacol Ther 1994;8:609-15.

207. Grover Z, Muir R, Lewindon P. Exclusive enteral nutrition induces early clinical, mucosal and transmural remission in paediatric Crohn's disease. J Gastroenterol 2014;49:638-45.

208. Berni Canani R, Terrin G, Borrelli O, et al. Short- and long-term therapeutic efficacy of nutritional therapy and corticosteroids in paediatric Crohn's disease. Digest Liver Dis 2006;38:381-7.

209. Hojsak I, Pavic AM, Misak Z, et al. Risk factors for relapse and surgery rate in children with Crohn's disease. Eur J Pediatr 2014;173:617-21.

210. Thomas AG, Taylor F, Miller V. Dietary intake and nutritional treatment in childhood Crohn's disease. J Pediatr Gastroenterol Nutr 1993; $17: 75-81$.

211. Lambert B, Lemberg DA, Leach ST, et al. Longer-term outcomes of nutritional management of Crohn's disease in children. Dig Dis Sci 2012;57:2171-7.

212. Gerasimidis K, Talwar D, Duncan A, et al. Impact of exclusive enteral nutrition on body composition and circulating micronutrients in plasma and erythrocytes of children with active Crohn's disease. Inflamm Bowel Dis 2012;18:1672-81.

213. Werkstetter KJ, Schatz SB, Alberer M, et al. Influence of exclusive enteral nutrition therapy on bone density and geometry in newly diagnosed pediatric Crohn's disease patients. Ann Nutr Metab 2013;63:10-6.

214. de Bie C, Kindermann A, Escher J. Use of exclusive enteral nutrition in paediatric Crohn's disease in The Netherlands. J Crohns Colitis 2013;7:263-70.

215. Grover Z, Lewindon P. Two-year outcomes after exclusive enteral nutrition induction are superior to corticosteroids in pediatric Crohn's disease treated early with thiopurines. Dig Dis Sci 2015;60:3069-74.

216. Soo J, Malik BA, Turner JM, et al. Use of exclusive enteral nutrition is just as effective as corticosteroids in newly diagnosed pediatric Crohn's disease. Dig Dis Sci 2013;58:3584-91.

217. Whitten KE, Leach ST, Bohane TD, et al. Effect of exclusive entera nutrition on bone turnover in children with Crohn's disease. J Gastroenterol 2010;45:399-405. 
218. Johnson T, Macdonald S, Hill SM, et al. Treatment of active Crohn's disease in children using partial enteral nutrition with liquid formula: a randomised controlled trial. Gut 2006;55:356-61.

219. Hartman C, Berkowitz D, Weiss B, et al. Nutritional supplementation with polymeric diet enriched with transforming growth factor-beta 2 for children with Crohn's disease. Isr Med Assoc J 2008; 10:503-7.

220. Gupta K, Noble A, Kachelries KE, et al. A novel enteral nutrition protocol for the treatment of pediatric Crohn's disease. Inflamm Bowel Dis 2013;19:1374-8.

221. Sigall-Boneh R, Pfeffer-Gik T, Segal I, et al. Partial enteral nutrition with a Crohn's disease exclusion diet is effective for induction of remission in children and young adults with Crohn's disease. Inflamm Bowel Dis 2014;20:1353-60.

222. Yamamoto T, Nakahigashi M, Umegae S, et al. Enteral nutrition for the maintenance of remission in Crohn's disease: a systematic review. Eur J Gastroenterol Hepatol 2010;22:1-8.

223. Wilschanski M, Sherman P, Pencharz P, et al. Supplementary enteral nutrition maintains remission in paediatric Crohn's disease. Gut 1996;38:543-8.

224. Duncan H, Buchanan E, Cardigan T, et al. A retrospective study showing maintenance treatment options for paediatric CD in the first year following diagnosis after induction of remission with EEN: supplemental enteral nutrition is better than nothing! BMC Gastroenterol 2014;14:50.

225. Takagi S, Utsunomiya K, Kuriyama S, et al. Effectiveness of an 'half elemental diet' as maintenance therapy for Crohn's disease: a randomized-controlled trial. Aliment Pharmacol Ther 2006;24:1333-40.

226. Verma S, Kirkwood B, Brown S, et al. Oral nutritional supplementation is effective in the maintenance of remission in Crohn's disease. Dig Liver Dis 2000;32:769-74.

227. Miele E, Pascarella F, Giannetti E, et al. Effect of a probiotic preparation (VSL\#3) on induction and maintenance of remission in children with ulcerative colitis. Am J Gastroenterol 2009;104:437-43.

228. Oliva S, Di Nardo G, Ferrari F, et al. Randomised clinical trial: the effectiveness of Lactobacillus reuteri ATCC 55730 rectal enema in children with active distal ulcerative colitis. Aliment Pharmacol Ther 2012;35:327-34.

229. Bousvaros A, Guandalini S, Baldassano RN, et al. A randomized, double-blind trial of Lactobacillus GG versus placebo in addition to standard maintenance therapy for children with Crohn's disease. Inflamm Bowel Dis 2005;11:833-9.

230. Butterworth AD, Thomas AG, Akobeng AK. Probiotics for induction of remission in Crohn's disease. Cochrane Database Syst Rev 2008;(3):CD006634.

231. Dignass A, Lindsay JO, Sturm A, et al. Second European evidencebased consensus on the diagnosis and management of ulcerative colitis part 2: current management. J Crohns Colitis 2012;6:991-1030.

232. Dignass A, Van Assche G, Lindsay JO, et al. The second European evidence-based consensus on the diagnosis and management of Crohn's disease: current management. J Crohns Colitis 2010;4:28-62.

233. Doherty G, Bennett G, Patil S, et al. Interventions for prevention of post-operative recurrence of Crohn's disease. Cochrane Database Syst Rev (4):2009:CD006873.

234. Mallon P, McKay D, Kirk S, et al. Probiotics for induction of remission in ulcerative colitis. Cochrane Database Syst Rev (4):2007:CD005573.

235. Meijer BJ, Dieleman LA. Probiotics in the treatment of human inflammatory bowel diseases: update. J Clin Gastroenterol 2011; 45(suppl):S139-44.

236. Naidoo K, Gordon M, Fagbemi AO, et al. Probiotics for maintenance of remission in ulcerative colitis. Cochrane Database Syst Rev 2011;(12):CD007443.

237. Oresland T, Bemelman WA, Sampietro GM, et al. European evidence based consensus on surgery for ulcerative colitis. J Crohns Colitis 2015;9:4-25.

238. Rolfe VE, Fortun PJ, Hawkey CJ, et al. Probiotics for maintenance of remission in Crohn's disease. Cochrane Database Syst Rev 2006;(4): CD004826.

239. Singh S, Stroud AM, Holubar SD, et al. Treatment and prevention of pouchitis after ileal pouch-anal anastomosis for chronic ulcerative colitis. Cochrane Database Syst Rev (11):2015:CD001176.
240. Van Assche G, Dignass A, Bokemeyer B, et al. Second European evidence-based consensus on the diagnosis and management of ulcerative colitis part 3: special situations. J Crohns Colitis 2013;7:1-33.

241. Van Assche G, Dignass A, Reinisch W, et al., European Crohn's and Colitis Organisation (ECCO). The second European evidence-based consensus on the diagnosis and management of Crohn's disease: special situations. J Crohns Colitis 2010;4:63-101.

242. Huynh HQ, deBruyn J, Guan L, et al. Probiotic preparation VSL\#3 induces remission in children with mild to moderate acute ulcerative colitis: a pilot study. Inflamm Bowel Dis 2009;15:760-8.

243. Henker J, Muller S, Laass MW, et al. Probiotic Escherichia coli Nissle $1917(\mathrm{EcN})$ for successful remission maintenance of ulcerative colitis in children and adolescents: an open-label pilot study. Z Gastroenterol 2008:46:874-5.

244. Bibiloni R, Fedorak RN, Tannock GW, et al. VSL\#3 probiotic-mixture induces remission in patients with active ulcerative colitis. Am J Gastroenterol 2005;100:1539-46.

245. Guandalini S. Update on the role of probiotics in the therapy of pediatric inflammatory bowel disease. Expert Rev Clin Immunol 2010;6:47-54.

246. Sood A, Midha V, Makharia GK, et al. The probiotic preparation, VSL\#3 induces remission in patients with mild-to-moderately active ulcerative colitis. Clin Gastroenterol Hepatol 2009;7:1202-99 e1.

247. Tursi A, Brandimarte G, Papa A, et al. Treatment of relapsing mild-tomoderate ulcerative colitis with the probiotic VSL\#3 as adjunctive to a standard pharmaceutical treatment: a double-blind, randomized, placebo-controlled study. Am J Gastroenterol 2010;105:2218-27.

248. Turner D, Travis SP, Griffiths AM, et al., European Crohn's and Colitis Organization; Porto IBD Working Group, European Society of Pediatric Gastroenterology, Hepatology, and Nutrition. Consensus for managing acute severe ulcerative colitis in children: a systematic review and joint statement from ECCO, ESPGHAN, and the Porto IBD Working Group of ESPGHAN. Am J Gastroenterol 2011;106:574-88.

249. Michail S, Sylvester F, Fuchs G, et al. Clinical efficacy of probiotics: review of the evidence with focus on children. J Pediatr Gastroenterol Nutr 2006;43:550-7.

250. Turner D, Levine A, Escher JC, et al. Management of pediatric ulcerative colitis: joint ECCO and ESPGHAN evidence-based consensus guidelines. J Pediatr Gastroenterol Nutr 2012;55:340-61.

251. Shen J, Ran HZ, Yin MH, et al. Meta-analysis: the effect and adverse events of Lactobacilli versus placebo in maintenance therapy for Crohn disease. Intern Med J 2009;39:103-9.

252. Bourreille A, Cadiot G, Le Dreau G, et al. Saccharomyces boulardii does not prevent relapse of Crohn's disease. Clin Gastroenterol Hepatol 2013;11:982-7.

253. Faghfoori Z1, Navai L, Shakerhosseini R, et al. Effects of an oral supplementation of germinated barley foodstuff on serum tumour necrosis factor-alpha, interleukin- 6 and -8 in patients with ulcerative colitis. Ann Clin Biochem 2011;48 (pt 3):233-7.

254. Ishikawa $\mathrm{H}$, Matsumoto $\mathrm{S}$, Ohashi $\mathrm{Y}$, et al. Beneficial effects of probiotic bifidobacterium and galacto-oligosaccharide in patients with ulcerative colitis: a randomized controlled study. Digestion 2011;84: $128-33$.

255. Benjamin JL, Hedin CR, Koutsoumpas F, et al. Randomised, doubleblind, placebo-controlled trial of fructo-oligosaccharides in active Crohn's disease. Gut 2011;60:923-9.

256. Steed H, Macfarlane GT, Blackett KL, et al. Clinical trial: the microbiological and immunological effects of synbiotic consumption-a randomized double-blind placebo-controlled study in active Crohn's disease. Aliment Pharmacol Ther 2010;32:872-83.

257. Fujimori S, Gudis K, Mitsui K, et al. A randomized controlled trial on the efficacy of synbiotic versus probiotic or prebiotic treatment to improve the quality of life in patients with ulcerative colitis. Nutrition 2009;25:520-5.

258. Chermesh I, Tamir A, Reshef R, et al. Failure of Synbiotic 2000 to prevent postoperative recurrence of Crohn's disease. Dig Dis Sci 2007;52:385-9.

259. Furrie E, Macfarlane S, Kennedy A, et al. Synbiotic therapy (Bifidobacterium longum/Synergy 1) initiates resolution of inflammation in patients with active ulcerative colitis: a randomised controlled pilot trial. Gut 2005;54:242-9. 
260. Hafer A, Krämer S, Duncker M, et al. Effect of oral lactulose on clinical and immunohistochemical parameters in patients with inflammatory bowel disease. BMC Gastroenterol 2007;7:36.

261. Ghouri YA, Richards DM, Rahimi EF, et al. Systematic review of randomized controlled trials of probiotics, prebiotics, and synbiotics in inflammatory bowel disease. Clin Exp Gastroenterol 2014;7:473-87.

262. Wedlake L, Slack N, Andreyev HJ, Whelan K. Fiber in the treatment and maintenance of inflammatory bowel disease: a systematic review of randomized controlled trials. Inflamm Bowel Dis 2014;20:576-86.

263. Brotherton CS, Taylor AG, Bourguignon C, et al. A high-fiber diet may improve bowel function and health-related quality of life in patients with Crohn disease. Gastroenterol Nurs 2014;37:206-16.

264. Bartel G, Weiss I, Turetschek K, et al. Ingested matter affects intestinal lesions in Crohn's disease. Inflamm Bowel Dis 2008;14:374-82.

265. Seidner DL, Lashner BA, Brzezinski A, et al. An oral supplement enriched with fish oil, soluble fiber, and antioxidants for corticosteroid sparing in ulcerative colitis: a randomized, controlled trial. Clin Gastroenterol Hepatol 2005;3:358-69.

266. Kanauchi O, Suga T, Tochihara M, et al. Treatment of ulcerative colitis by feeding with germinated barley foodstuff: first report of a multicenter open control trial. J Gastroenterol 2002;37:67-72.

267. Fernández-Bañares F, Hinojosa J, Sánchez-Lombraña JL, et al. Randomized clinical trial of Plantago ovata seeds (dietary fiber) as compared with mesalamine in maintaining remission in ulcerative colitis. Am J Gastroenterol 1999;94:427-33.

268. Ejderhamn J, Hedenborg G, Strandvik B. Long-term double-blind study on the influence of dietary fibres on faecal bile acid excretion in juvenile ulcerative colitis. Scand J Clin Lab Invest 1992;52:697-706.

269. Ritchie JK, Wadsworth J, Lennard-Jones JE, et al. Controlled multicentre therapeutic trial of an unrefined carbohydrate, fibre rich diet in Crohn's disease. Br Med J 1987;1987:517-20.

270. Levenstein S, Prantera C, Luzi C, et al. Low residue or normal diet in Crohn's disease: a prospective controlled study in Italian patients. Gut 1985;26:989-93.

271. Jones VA, Dickinson RJ, Workman E, et al. Crohn's disease: maintenance of remission by diet. Lancet 1985;2:177-80.

272. Liu X, Wu Y, Li F, et al. Dietary fiber intake reduces risk of inflammatory bowel disease: result from a meta-analysis. Nutr Res 2015;35:753-8.

273. Charlebois A, Rosenfeld G, Bressler B. The impact of dietary interventions on the symptoms of inflammatory bowel disease: a systematic review. Crit Rev Food Sci Nutr 2016;56:1370-8.

274. Thies F, Masson LF, Boffetta P, et al. Oats and bowel disease: a systematic literature review. Br J Nutr 2014;112:31-43.

275. Penagini F, Dilillo D, Borsani B, et al. Nutrition in pediatric inflammatory bowel disease: from etiology to treatment. A systematic review. Nutrients 2016;8:pii: E334; doi: 10.3390/nu8060334.

276. Durchschein F, Petritsch W, Hammer HF. Diet therapy for inflammatory bowel diseases: the established and the new. World J Gastroenterol 2016;22:2179-94.

277. Hou JK, Lee D, Lewis J. Diet and inflammatory bowel disease: review of patient-targeted recommendations. Clin Gastroenterol Hepatol 2014;12:1592-600.

278. Ruemmele FM. Role of diet in inflammatory bowel disease. Ann Nutr Metab 2016;68(suppl 1):33-41.

279. Suskind DL, Wahbeh G, Cohen SA, et al. Patients perceive clinical benefit with the specific carbohydrate diet for inflammatory bowel disease. Dig Dis Sci 2016;61:3255-60.

280. Obih C, Wahbeh G, Lee D, et al. Specific carbohydrate diet for pediatric inflammatory bowel disease in clinical practice within an academic IBD center. Nutrition 2016;32:418-25.

281. Cohen SA, Gold BD, Oliva S, et al. Clinical and mucosal improvement with specific carbohydrate diet in pediatric Crohn disease. J Pediatr Gastroenterol Nutr 2014;59:516-21.

282. Vernia P, Loizos P, Di Giuseppantonio I, et al. Dietary calcium intake in patients with inflammatory bowel disease. J Crohns Colitis 2014; $8: 312-7$.

283. Pawlowska K, Umlawska W, Iwanczak B. Prevalence of lactose malabsorption and lactose intolerance in pediatric patients with selected gastrointestinal diseases. Adv Clin Exp Med 2015;24:863-71.
284. Wiecek S, Wos H, Radziewicz Winnicki I, et al. Disaccharidase activity in children with inflammatory bowel disease. Turk J Gastroenterol 2014;25:185-91.

285. Gibson PR, Shepherd SJ. Personal view: food for thought-western lifestyle and susceptibility to Crohn's disease. The FODMAP hypothesis. Aliment Pharmacol Ther 2005;21:1399-409.

286. Gearry RB, Irving PM, Barrett JS, et al. Reduction of dietary poorly absorbed short-chain carbohydrates (FODMAPs) improves abdominal symptoms in patients with inflammatory bowel disease-a pilot study. J Crohns Colitis 2009;3:8-14.

287. Prince AC, Myers CE, Joyce T, et al. Fermentable carbohydrate restriction (low FODMAP diet) in clinical practice improves functional gastrointestinal symptoms in patients with inflammatory bowel disease. Inflamm Bowel Dis 2016;22:1129-36.

288. Halmos EP, Christophersen CT, Bird AR, et al. Consistent prebiotic effect on gut microbiota with altered FODMAP intake in patients with Crohn's disease: a randomised, controlled cross-over trial of welldefined diets. Clin Transl Gastroenterol 2016;7:e164.

289. Pfeffer-Gik T, Levine A. Dietary clues to the pathogenesis of Crohn's disease. Dig Dis 2014;32:389-94.

290. Gunasekeera V, Mendall MA, Chan D, et al. Treatment of Crohn's disease with an IgG4-guided exclusion diet: a randomized controlled trial. Dig Dis Sci 2016;61:1148-57.

291. Hou JK, Abraham B, El-Serag H. Dietary intake and risk of developing inflammatory bowel disease: a systematic review of the literature. Am J Gastroenterol 2011;106:563-73.

292. Persson PG, Ahlbom A, Hellers G. Diet and inflammatory bowel disease: a case-control study. Epidemiology 1992;3:47-52.

293. Amre DK, D'Souza S, Morgan K, et al. Imbalances in dietary consumption of fatty acids, vegetables, and fruits are associated with risk for Crohn's disease in children. Am J Gastroenterol 2007; 102:2016-25.

294. Shoda R, Matsueda K, Yamato S, et al. Epidemiologic analysis of Crohn disease in Japan: increased dietary intake of n-6 polyunsaturated fatty acids and animal protein relates to the increased incidence of Crohn disease in Japan. Am J Clin Nutr 1996;63:741-5.

295. Sakamoto N, Kono S, Wakai K, et al. Dietary risk factors for inflammatory bowel disease: a multicenter case-control study in Japan. Inflamm Bowel Dis 2005;11:154-63.

296. Ananthakrishnan AN, Khalili H, Konijeti GG, et al. Long-term intake of dietary fat and risk of ulcerative colitis and Crohn's disease. Gut 2013;63:776-84.

297. Jantchou P, Morois S, Clavel-Chapelon F, et al. Animal protein intake and risk of inflammatory bowel disease: The E3N prospective study. Am J Gastroenterol 2010;105:2195-201.

298. Ananthakrishnan AN, Khalili H, Konijeti GG, et al. A prospective study of long-term intake of dietary fiber and risk of Crohn's disease and ulcerative colitis. Gastroenterology 2013;145: 970-7.

299. Racine A, Carbonnel F, Chan SS, et al. Dietary patterns and risk of inflammatory bowel disease in Europe: results from the EPIC study. Inflamm Bowel Dis 2016;22:345-54.

300. Chassaing B, Koren O, Goodrich JK, et al. Dietary emulsifiers impact the mouse gut microbiota promoting colitis and metabolic syndrome. Nature 2015;519:92-6.

301. Roberts CL, Keita AV, Duncan SH, et al. Translocation of Crohn's disease Escherichia coli across M-cells: contrasting effects of soluble plant fibres and emulsifiers. Gut 2010;59:1331-9.

302. Nickerson KP, Homer CR, Kessler SP, et al. The dietary polysaccharide maltodextrin promotes Salmonella survival and mucosal colonization in mice. PloS One 2014;9:e101789.

303. Roberts CL, Rushworth SL, Richman E, et al. Hypothesis: increased consumption of emulsifiers as an explanation for the rising incidence of Crohn's disease. J Crohns Colitis 2013;7:338-41.

304. Cashman KD, Shanahan F. Is nutrition an aetiological factor for inflammatory bowel disease? Eur J Gastroenterol Hepatol 2003; 15:607-13.

305. Maconi G, Ardizzone S, Cucino C, et al. Pre-illness changes in dietary habits and diet as a risk factor for inflammatory bowel disease: a casecontrol study. World J Gastroenterol 2010;16:4297-304. 